\title{
Multiple Environmental Influences on the Lightning of Cold-Based Continental Cumulonimbus Clouds. Part I: Description and Validation of Model
}

\author{
Vaughan T. J. Phillips, ${ }^{\mathrm{a}}$ Marco Formenton, ${ }^{\mathrm{a}}$ ViJay P. Kanawade,,${ }^{\mathrm{a} h}$ Linus R. Karlsson, ${ }^{\mathrm{a}}$ \\ Sachin Patade, ${ }^{a}$ Jiming Sun, ${ }^{b}$ Christelle Barthe, ${ }^{c}$ Jean-Pierre Pinty, ${ }^{\mathrm{d}}$ Andrew G. Detwiler, ${ }^{\mathrm{e}}$ \\ Weitao Lyu, ${ }^{f}$ AND SARAH A. TESSENDORF ${ }^{\mathrm{g}}$ \\ ${ }^{\mathrm{a}}$ Department of Physical Geography, University of Lund, Lund, Sweden; ${ }^{\mathrm{b}}$ Institute of Atmospheric Physics, Chinese Academy of \\ Sciences, Beijing, China; ${ }^{\mathrm{c}}$ Laboratoire de l'Atmosphère et des Cyclones, UMR 8105 CNRS/Météo-France/Université de La Réunion, \\ Saint Denis, Réunion, France; ${ }^{\mathrm{d}}$ Laboratoire d'Aérologie, Université Paul Sabatier and CNRS, Toulouse, France; ${ }^{\mathrm{e}}$ Department of \\ Physics, South Dakota School of Mines and Technology, Rapid City, South Dakota ${ }^{\mathrm{f}}{ }^{\mathrm{S}}$ State Key Laboratory of Severe Weather, \\ Chinese Academy of Meteorological Sciences, Beijing, China; ${ }^{\mathrm{g}}$ National Center for Atmospheric Research, Boulder, Colorado
}

(Manuscript received 1 August 2019, in final form 5 June 2020)

\begin{abstract}
In this two-part paper, influences from environmental factors on lightning in a convective storm are assessed with a model. In Part I, an electrical component is described and applied in the Aerosol-Cloud model (AC). AC treats many types of secondary (e.g., breakup in ice-ice collisions, raindrop-freezing fragmentation, rime splintering) and primary (heterogeneous, homogeneous freezing) ice initiation. AC represents lightning flashes with a statistical treatment of branching from a fractal law constrained by video imagery.

The storm simulated is from the Severe Thunderstorm Electrification and Precipitation Study (STEPS; 19/20 June 2000). The simulation was validated microphysically [e.g., ice/droplet concentrations and mean sizes, liquid water content (LWC), reflectivity, surface precipitation] and dynamically (e.g., ascent) in our 2017 paper. Predicted ice concentrations $\left(\sim 10 \mathrm{~L}^{-1}\right)$ agreed - to within a factor of about 2-with aircraft data at flight levels $\left(-10^{\circ}\right.$ to $\left.-15^{\circ} \mathrm{C}\right)$. Here, electrical statistics of the same simulation are compared with observations. Flash rates (to within a factor of 2), triggering altitudes and polarity of flashes, and electric fields, all agree with the coincident STEPS observations.

The "normal" tripole of charge structure observed during an electrical balloon sounding is reproduced by AC. It is related to reversal of polarity of noninductive charging in ice-ice collisions seen in laboratory experiments when temperature or LWC are varied. Positively charged graupel and negatively charged snow at most midlevels, charged away from the fastest updrafts, is predicted to cause the normal tripole. Total charge separated in the simulated storm is dominated by collisions involving secondary ice from fragmentation in graupel-snow collisions.
\end{abstract}

KEYWORDS: Atmospheric electricity; CAPE; Cloud microphysics; Freezing precipitation; Ice crystals; Ice particles

\section{Introduction}

The first known books about weather phenomena were by Aristotle and his student, Theophrastus, in Ancient Greece around 300 BC (Brunschon and Sider 2007). In Meteorology, Theophrastus listed possible causes of lightning (Fortenbaugh and Gutas 1992). A connection between ice in clouds and lightning was hypothesized. In modern times, lightning was understood as an electrical process. In the twentieth century, various causes were proposed for charge separation in clouds [literature reviewed by Pruppacher and Klett (1997, hereafter PK97)]: 1) diffusion of ions onto inductively polarized drops, 2) convection of space charge from the environment, 3) polarized drops colliding with ice and rebounding, 4) ice breakup, and 5) "noninductive" charge separation in rebounding ice-ice collisions. Only cause 5 explained observed time scales of electrification (Helsdon et al. 2001, hereafter H01). Whereas an explanation of lightning by Theophrastus assumed collisions

\footnotetext{
${ }^{\mathrm{h}}$ Current affiliation: Centre for Earth, Ocean and Atmospheric Sciences, University of Hyderabad, Hyderabad, India.
}

Corresponding author: Vaughan T. J. Phillips, vaughan.phillips@ nateko.lu.se involving ice somehow, some modern explanations did not involve ice (causes 1 and 2) and have been discounted.

With emergence of cloud physics, it has become apparent that no physical process occurs in isolation in clouds. Lightning is no exception. Clouds consist of a myriad of interconnected physical processes, including electrical processes. The charge separation that causes lightning is known to be predominantly due to (noninductive) rebounding ice-ice collisions involving rimed ice precipitation in the presence of supercooled liquid (Reynolds et al. 1957; Takahashi 1978, 1984; Latham 1981; Jayaratne et al. 1983; Baker et al. 1987; Helsdon and Farley 1987; Latham and Dye 1989; Kumar and Saunders 1989; H01; Helsdon et al. 2002, hereafter H02; Mansell et al. 2002, 2005, 2010, hereafter M02, M05, M10, respectively). Sedimentation of heavier particles leaves a net charge aloft. Overall charge separated depends on concentrations of ice, while charge separated per collision is governed by temperature $(T)$, liquid water content (LWC), and particle sizes. Essentially, lightning is caused by microphysical interactions.

Microphysical processes in clouds are controlled by environmental factors, such as aerosol conditions, instability, shear, and humidity. Aerosol conditions govern numbers and sizes of cloud particles (Rosenfeld and Lensky 1998; Phillips et al. 2001, 2002, 2005; Khain et al. 2004, 2005, 2008; 
van den Heever et al. 2006; Kudzotsa et al. 2016). There are two aerosol-sensitive mechanisms of precipitation:

- Cloud droplets coalesce to form rain depending on solute aerosol concentrations, if cloud base is warm ("warm rain process"). Supercooled rain in warm-based clouds (Koenig 1963; Hallett et al. 1978; Blyth and Latham 1993; Blyth et al. 1997; Williams et al. 1999) can freeze (Bringi et al. 1997) into ice precipitation (Phillips et al. 2001, 2002, 2005).

- For cold (e.g., $\leq 0^{\circ} \mathrm{C}$ ) cloud bases, the "ice-crystal process" involves growth of crystals (e.g., from solid aerosols) to "snow" (large crystals or aggregates) that may rime into graupel.

Relative humidity $(\mathrm{RH})$ controls the temperature of cloud base (Williams and Stanfill 2002; Khain et al. 2004; Williams et al. 2005; Zeng et al. 2009).

The vertical structure of charge characterizes thunderstorms. Most typically, a storm is "normal" (Williams 1989) with a tripole (lower positive charge beneath midlevel negative charge with upper-level positive charge) or dipole (Kuhlman et al. 2006), causing negative cloud-to-ground flashes (-CGs; negative charge to ground). Rarer storms with the opposite configuration are "inverted" (Marshall et al. 1995), with negative charge at upper levels and "+CGs" (positive charge to ground). More intense convection can be inverted with mostly + CGs and often large hail (Rust et al. 1981; Reap and MacGorman 1989; Wiens et al. 2005).

For our cloud model, representations of ice-microphysical processes were developed (Phillips et al. 2013, 2014, 2015, 2017a, 2018). Sticking efficiency for ice-ice collisions was treated with an energy-based approach (Phillips et al. 2015). Breakup in ice-ice collisions was treated for all microphysical species and predicted by to form most $(95 \%-98 \%)$ of ice particles not from homogeneous freezing in a "cold-based" (cloud base of about $0^{\circ} \mathrm{C}$ ) mesoscale multicellular storm (Phillips et al. 2017a,b). The storm was observed on 19/20 June 2000 in the Severe Thunderstorm Electrification and Precipitation Study (STEPS) (Lang et al. 2004). The ice-crystal process prevailed in the overall production of precipitation.

In the simulated STEPS storm, inclusion of breakup in iceice collisions increased the average concentration of ice by between one and two orders of magnitude from $0^{\circ}$ to $-30^{\circ} \mathrm{C}$ (Phillips et al. 2017b, their Figs. 5d and 8). Only by including this breakup were aircraft observations of filtered $(>0.2 \mathrm{~mm})$ ice concentration and LWC predicted realistically. Collisions of snow $(>0.3 \mathrm{~mm})$ with denser graupel/hail initiated most of the secondary fragments. Surface precipitation was modified by breakup with smaller crystals and less LWC.

In this two-part paper, to compare influences on lightning from various environmental factors, an electrical component is first developed and assessed for our Aerosol-Cloud model (AC). AC represents all empirically quantified mechanisms for initiation of drops and crystals in terms of dependencies on aerosol conditions. This electrical assessment is performed with the same cold-based cloud case from STEPS simulated and validated by Phillips et al. (2017b) against coincident observations. AC reproduced the many nonelectrical cloud-microphysical statistics observed by aircraft in that case-including ice concentration and LWC. Here the simulation is repeated including the electrical component.

STEPS occurred in the U.S. central Great Plains (CGP), combining electrical (e.g., by balloon), radar, and microphysical observations with an armored aircraft sampling fast thunderstorm updrafts (Lang et al. 2004). A Lightning Mapping Array (LMA) was deployed (Rison et al. 1999; Krehbiel et al. 2000). The storm case (19/20 June) was selected as -CGs and normal electrical structure were observed. In CGP, most storms chiefly produce negative ( $-\mathrm{CG}$ ) lightning (Orville and Huffines 2001; Boccippio et al. 2001; Fleenor et al. 2009), which is shown to be due to normal polarity charge structure (Tessendorf et al. 2007).

The aim of this two-part paper is to unravel some of the mysteries about environmental influences on lightning. First in this Part I the model and STEPS simulation are explained and validated with observations. In Phillips and Patade (2020, manuscript submitted to J. Atmos. Sci., hereafter Part II), the simulation will be analyzed with sensitivity tests to quantify the environmentlightning linkage. Focus is given in Part II to reasons for why lightning is observed more frequently over land than ocean and to how the environment controls the charge structure of storms.

\section{Model description}

The description by Phillips et al. (2017b) applies here in nonelectrical respects with only a few minor changes. Symbols used in this paper are summarized in appendix A.

\section{a. AC model}

AC represents clouds and aerosols with hybrid spectral bin/two-moment bulk microphysics, interactive radiation, and semiprognostic aerosol schemes. Here AC is run as a cloudresolving model (CRM) with horizontal and vertical grid spacings of 1 and $0.5 \mathrm{~km}$, and a 3D mesoscale domain $80 \mathrm{~km}$ wide. Mesoscale cloud systems are resolved. Microphysical species are cloud liquid, cloud ice (or "crystals"), rain, graupel/hail and snow. Seven aerosol species govern primary initiation of hydrometeors, with heterogeneous and homogeneous nucleation of ice. Three types of fragmentation are treated to form secondary ice: breakup in ice-ice collisions (Phillips et al. 2017a,b), Hallett and Mossop (1974, hereafter HM) rime splintering (cloud droplets $>24 \mu \mathrm{m}$ ) and fragmentation of freezing rain/drizzle (Phillips et al. 2018). More details are in appendix B.

\section{b. Electrical component}

The degree of complexity of the lightning scheme resembles that of Barthe et al. (2005) and is intermediate between those of $\mathrm{H} 02$ and M02/M05. This compromise minimizes computational expense and facilitates understanding by excluding nonessential processes.

\section{1) Charge AND ITS SEPARATION IN ICE-ICE COLLISIONS}

Charge on hydrometeors is represented with a "space charge mixing ratio," $\rho_{q, x}$, for each $x$ th microphysical species. It is a "bulk" quantity (i.e., for all sizes) transferred between species by microphysical conversions. Charge density in air due 
to ions/charged aerosols, $\rho_{q, a}$, is assumed to have a source from evaporation of charged drops (from prior melting of charged ice) or sublimation of charged ice, but not from diffusional growth (e.g., Barthe et al. 2005). In the laboratory, during evaporation of any charged drop, only when it has completely disappeared is charge seen to transfer to the air, and the same would be expected for ice. Hence in AC, during any evaporation/sublimation of particle size distributions (PSDs), it is assumed that there are always some hydrometeors small enough to disappear totally. No recombination of charge in air is represented, since negative or positive ions/charged aerosols are not separately resolved. No sinks of ions on cloud particles are treated.

For ice-ice collisions, the emulated bin scheme involves temporary grids of bins discretizing size distributions (section 2a) and schemes for sticking (Phillips et al. 2015) and collision (Khain et al. 2001; Pinsky et al. 2001) efficiencies. "Bulk" charge separated in collisions is from summing contributions over permutations of bin pairs. Only $\rho_{q, x}$ is then altered. Charge per particle, $q(D)=\beta D^{\gamma}$, is assumed in any species (Beard and Ochs 1986; MacGorman and Rust 1998; Barthe et al. 2005, 2012); $D$ is particle diameter, $\gamma$ is prescribed with a fixed value, and $\beta$ is evaluated numerically from $\rho_{q, x}$. The bulk charge is distributed among all particles of a temporary grid of bins, so that larger particles have more charge per particle.

There are two main groups of schemes for noninductive charge separation from laboratory studies:

1) Takahashi $(1978,1984)$;

2) Jayaratne et al. (1983), Keith and Saunders (1989), Saunders et al. (1991), Brooks et al. (1997), and Saunders and Peck (1998).

At weak LWCs (e.g., $0.1 \mathrm{~g} \mathrm{~m}^{-3}$ ) Takahashi observed positive charging of the rimer at most temperatures while Saunders et al. show negative charging. Reasons for such differences are uncertain. Experiments differ in design between the two groups, 1 and 2 (e.g., Saunders et al. 2006).

We opted for group 1. This allowed -CGs and a "normal tripole" structure to be simulated, as observed in the case (sections 1 and 4). A faster impact speed in group $1\left(8 \mathrm{~m} \mathrm{~s}^{-1}\right)$ approaches convective updraft speeds $\left(10-15 \mathrm{~m} \mathrm{~s}^{-1}\right)$ observed here (Tessendorf et al. 2007; Phillips et al. 2017b), similar to fall speeds of graupel/hail balanced in them. Real flash rates increase with updraft speed (Williams et al. 1985; Zipser and Lutz 1994; Boccippio et al. 2001). Hail below normal thunderstorms is seen to be mostly positively charged (Kuettner 1950; Rust and Moore 1974; Magono 1977; Wahlin 1986), consistent with positive charging of graupel/hail simulated by AC (section 5b). Laboratory observations by Pereyra et al. (2000), Berdeklis and List (2001) and Takahashi and Miyawaki (2002) at weak LWCs agreed better with group 1 than group 2.

Takahashi (1978) observed the average charge, $Q_{\text {Taka }}$, separated per collision between a rimed rod $(3 \mathrm{~mm}$, representing graupel) and crystals $(100 \mu \mathrm{m})$ from $0^{\circ}$ to $-30^{\circ} \mathrm{C}$. Charging was seen to depend on $T\left({ }^{\circ} \mathrm{C}\right)$ and $\mathrm{LWC}$, with positive charging of the rimer for $T>-10^{\circ} \mathrm{C}$ but only for low or very high LWCs otherwise. Charge separated per ice-ice collision, whether or not rebounding, was extrapolated with a dimensionless parameter, $\alpha$ :

$$
\begin{aligned}
\delta Q= & \alpha \operatorname{MIN}\left[Q_{\mathrm{Taka}}\left(T, \mathrm{LWC}^{*}\right), Q_{\mathrm{Taka}}(T, \mathrm{LWC})\right] \\
& \times[(1-\xi)+\xi \psi] \forall 0^{\circ}>T>-30^{\circ} \mathrm{C},
\end{aligned}
$$

where $Q_{\text {Taka }}$ is the function plotted by Takahashi (1978, Fig. 8 therein $)$, fitting his own data. Here $\xi\left(T>-20^{\circ} \mathrm{C}\right)=0$ and $\xi\left(T<-25^{\circ} \mathrm{C}\right)=1$, while $\psi\left(\mathrm{LWC}<0.01 \mathrm{~g} \mathrm{~m}^{-3}\right)=0$ and $\psi\left(\mathrm{LWC}>0.05 \mathrm{~g} \mathrm{~m}^{-3}\right)=1$. Both are linearly interpolated in between. Here the actual LWC in Takahashi's original formula has been replaced with LWC* in Eq. (1) when doing so decreases $Q_{\text {Taka. }}$. At $T>-20^{\circ} \mathrm{C}, \mathrm{LWC}^{*}=\mathrm{LWC}$. Takahashi counted all collisions irrespective of whether they rebound, so Eq. (1) applies to all collisions too.

For $T<-24^{\circ} \mathrm{C}$ and LWC $<0.2 \mathrm{~g} \mathrm{~m}^{-3}$, practically no observations were made by Takahashi (1978), who extrapolated $Q_{\text {Taka }}$ into this unobserved region assuming positive charging of the rimer. Negative charging was observed for $\mathrm{LWC} \geq$ $0.2 \mathrm{~g} \mathrm{~m}^{-3}$ at $T<-24^{\circ} \mathrm{C}$. By videosonde in cold-based $\left(0^{\circ} \mathrm{C}\right)$ clouds (tops near $-25^{\circ} \mathrm{C}$ ), graupel was seen to be charged negatively below and positively above the $-11^{\circ} \mathrm{C}$ level (Takahashi et al. 2017). Peak LWC was $0.4 \mathrm{~g} \mathrm{~m}^{-3}$ so this reversal $\left(-11^{\circ} \mathrm{C}\right)$ was warmer than for Takahashi's (1978) lab data (see also Pereyra et al. 2008).

Consequently, at weak LWCs if $T<-20^{\circ} \mathrm{C}$ the unobserved charging of the rimer is assumed to be negative with values from the adjacent observed region at $0.2-0.5 \mathrm{~g} \mathrm{~m}^{-3}$ (section $5 b)$ :

$\mathrm{LWC}^{*}\left[\mathrm{~g} \mathrm{~m}^{-3}\right]=\left\{\begin{array}{l}\mathrm{LWC} \times[1-\xi(T)]+0.5 \xi(T) \\ \forall 0.01<\mathrm{LWC}<0.5 \mathrm{~g} \mathrm{~m}^{-3} \text { and } T<-20^{\circ} \mathrm{C} . \\ \mathrm{LWC}, \quad \text { otherwise }\end{array}\right.$

Equation (2) improves a simulation, not shown here, of an inverted storm with + CGs observed by Wiens et al. (2005). With more prolific negative charging of the rimer at weaker LWCs, the central positive charge of the inverted storm from fallout of graupel/hail is strengthened, favoring + CGs.

Takahashi (1984) proposed that charge separated is proportional to the difference in fall speeds and surface area of the crystal. Thus, diameter $\left(D_{i}\right)$ and fall speeds govern $\alpha$ :

$$
\begin{aligned}
\alpha & =\operatorname{MIN}\left[3 \Xi\left(\frac{D_{i, *}}{D_{0}}\right)^{2} \frac{\left|V_{p}-V_{i}\right|}{8}, 100\right], \\
D_{i, *} & =\operatorname{MIN}\left(D_{i}, 0.3 D_{p}\right) .
\end{aligned}
$$

Unrimed (cloud ice/snow) and rimed (graupel/hail or riming snow) particles are denoted by subscripts " $i$ " and " $p$." Also $D_{0}=100 \mu \mathrm{m}$. The contact area cannot be wider than some a fraction of the rimer, hence $D_{i, *}$. Inspection of laboratory data by Takahashi (1987, his Fig. A3) implies it is 0.3 .

As Takahashi (1978) observed collisions of only cloud-ice crystals $(0.1 \mathrm{~mm})$ with a rimer, our inclusion of a new factor, $\Xi$, 
in Eq. (3) treats other types of collision too. For collisions of graupel with cloud-ice crystals, $\Xi=1$. For graupel-snow collisions, the charge transferred is assumed proportional to the bulk density of snow, which determines the total area of many microscopic solid contacts, not counting air spaces, during impact. Indeed, the charge transferred by collision of a 1-mm frost particle with a large rimed target (Takahashi 1987, his Fig. A3) is seen to be lower by a factor of 25 than expected by areal extrapolation from $0.1 \mathrm{~mm}$ (Takahashi 1978). This factor approximates the ratio of bulk densities between a $1-\mathrm{mm}$ snow particle and a $0.1-\mathrm{mm}$ crystal in AC (800:40) (see also Heymsfield et al. 2002, their Fig. B1). Hence we assign $\Xi=\rho_{s} / 800$ for graupel-snow collisions and $\Xi=\rho_{s} / 600$ for snow-crystal collisions. Here $\rho_{s}$ is the bulk density of snow $\left(\mathrm{kg} \mathrm{m}^{-3}\right)$ while 800 and $600 \mathrm{~kg} \mathrm{~m}^{-3}$ are the estimated bulk densities of cloud-ice crystals $(0.1 \mathrm{~mm})$ and rime density of the target (Williams and Zhang 1996) respectively, in the laboratory experiment of Takahashi (1978).

At $T<-30^{\circ} \mathrm{C}$, then $\delta Q$ is multiplied by $f_{\text {Taka }}(T)$, which is zero when colder than $-40^{\circ} \mathrm{C}$ and unity at $-30^{\circ} \mathrm{C}$, being interpolated in between $\left(f_{\text {Taka }}=1-[(T+30) / 10]^{2}\right.$ for $-30^{\circ}>$ $\left.T>-40^{\circ} \mathrm{C}\right)$. Also, $Q_{\text {Taka }}\left(T<-30^{\circ} \mathrm{C}, \mathrm{LWC}\right)=Q_{\text {Taka }}\left(-30^{\circ} \mathrm{C}\right.$, LWC). From Eq. (1), $\pm \delta Q$ is added to $\rho_{q, x}$ per collision among different species unless the sticking efficiency is unity (Phillips et al. 2015). When the entire rimer is covered in liquid (Phillips et al. 2014) or when $\mathrm{LWC}<0.01 \mathrm{~g} \mathrm{~m}^{-3}$, then $\delta Q=0$ is assumed.

Equations (2) and (4) are unique here. The original factor of $\left(D_{i} / D_{0}\right)^{2}$ for $\alpha$ in (3) must have somehow represented the ratio of areas of contact between the actual and observed $\left(D_{0}=\right.$ $100 \mu \mathrm{m})$ collisions. Charge separation is an interfacial phenomenon. Takahashi (1984) thresholded $\alpha$ to be $<10$ since Marshall et al. (1978) attributed saturation of charging to a limitation on contact area. We relax the threshold to 100 as it was not directly observed and a similar limitation is present in (4). The physically plausible dependency on contact area, and similarity of morphologies of snow and crystals on the microscopic scale, suggests the validity of extrapolating beyond laboratory conditions to any crystal size and perhaps to graupel-snow collisions. Yet charging in graupel-snow collisions was never studied by Takahashi (1978). Conceivably, a slightly different dependence of charging on contact area for snow than crystals may exist in reality (Takahashi 1987). Two key morphological differences between "cloud-ice" crystals $(<0.3 \mathrm{~mm})$ and snow $(>0.3 \mathrm{~mm}$ in $\mathrm{AC})$ exist: bulk density drastically decreases for snow aggregates as size increases and the presence of multiple monomers per snowflake boosts the sticking efficiency (Phillips et al. 2015).

In summary, Eqs. (1)-(4) are applied for charging in collisions between graupel/hail and crystals, graupel/hail and snow, and riming snow and crystals. Only charging in graupel-crystal collisions was observed in the laboratory by Takahashi, however.

\section{2) ELECTRIC FIELD}

AC uses two domains, a "dynamics domain" for prognostic variables inside an extended finer "potential domain" for electrical quantities. The potential domain $(120 \mathrm{~km} \times 80 \mathrm{~km} \times 30 \mathrm{~km}$; a $3 \mathrm{D}$ cubic grid of $0.5-\mathrm{km}$ resolution) is much wider (by $50 \%$ ) and higher than the dynamics domain for open lateral (eastern and western) and upper boundaries, following M05. Northern and southern lateral boundaries coincide and are periodic for both domains. The electric field, $\mathbf{E}=-\nabla \phi$, is calculated on the potential domain with potential, $\phi$, from solving the Poisson equation for net space charge density, $\rho_{q}$ (Adams 1989). For the potential domain, horizontal components of electric field are zero on lateral open boundaries (M05, M10) far from the dynamics domain, while upper and lower boundaries are prescribed with the background potential and zero volts, respectively. In clear-sky conditions the fair-weather electric field is reproduced (e.g., about -50 and $-5 \mathrm{~V} \mathrm{~m}^{-1}$ at 1.6 and $10 \mathrm{~km}$ MSL; e.g., PK97). The upper boundary $(30 \mathrm{~km}$ above ground) is so high that fixing its potential has little influence on the storm (cloud tops about $14 \mathrm{~km}$ above ground).

Only after each flash and its partial neutralization of charge is $\phi$ evaluated. This is less expensive than frequent updates of electric field in more explicit models (e.g., M02; Fierro et al. 2006). Though electric fields may influence coagulation (reviewed by PK97), such effects are neglected here.

\section{3) LightNing}

Lightning is simulated partly following MacGorman et al. (2001) and Barthe et al. (2005) with some modifications. The discharge is triggered where $E=|\mathbf{E}|$ reaches a threshold (Marshall et al. 1995; Riousset et al. 2007; Krehbiel et al. 2008) in $\mathrm{V} \mathrm{m}^{-1}$ of

$$
E_{\text {init }}=1.8 \times 10^{5} \rho_{a}(z)
$$

The plasma channel is modeled as two leaders with opposite polarities of charge propagating from the trigger in opposite directions. The positive and negative leaders propagate toward negative and positive ambient charge, respectively, if preflash fields exceed a fraction, $f_{\text {prop }}=5 \%$, of $E_{\text {init }}$; Winn et al. (1978) observed $15 \mathrm{kV} \mathrm{m}^{-1}$ fields below a thunderstorm. Propagation stops if the channel doubles back. Each leader is traced exactly parallel or antiparallel to the preflash electric field vector irrespective of gridpoint locations. The same lateral boundary conditions are applied to leaders and their branches as for other predicted quantities. Any leader crossing a periodic boundary simply reenters on the other side.

A $-\mathrm{CG}(+\mathrm{CG})$ occurs if a leader goes below $1.5 \mathrm{~km}(3 \mathrm{~km})$ above ground. This threshold is from observations by a lightning positioning system at Guangzhou (Lyu et al. 2014, 2016; Fan et al. 2018) and in STEPS (Wiens et al. 2005). Also the potential of the trigger point, $\phi_{0}$, must satisfy $\phi_{0} \times \rho_{\text {ch }} \geq 0$ where $\rho_{\text {ch }}$ is charge density in the leader approaching ground (positive for + CGs, negative for $-\mathrm{CGs}$ ) and $\left|\phi_{0}\right|>20 \mathrm{M} \mathrm{V}$ (Tan et al. 2014, their Fig. 3). If both criteria are met, the leader is sent vertically to ground.

Branches are treated statistically, without tracing channels, when $\left|\rho_{q}\right|>\rho_{\text {crit }}=0.2 \mathrm{nC} \mathrm{kg}^{-1}$ and ambient $\phi$ is lower (higher) than the positive (negative) leader's $\phi_{0}$. A grid box must satisfy both conditions and be adjacent to one satisfying them so as to be added to the branch cluster of a leader. The maximum number of branching grid boxes is (Barthe et al. 2005) 


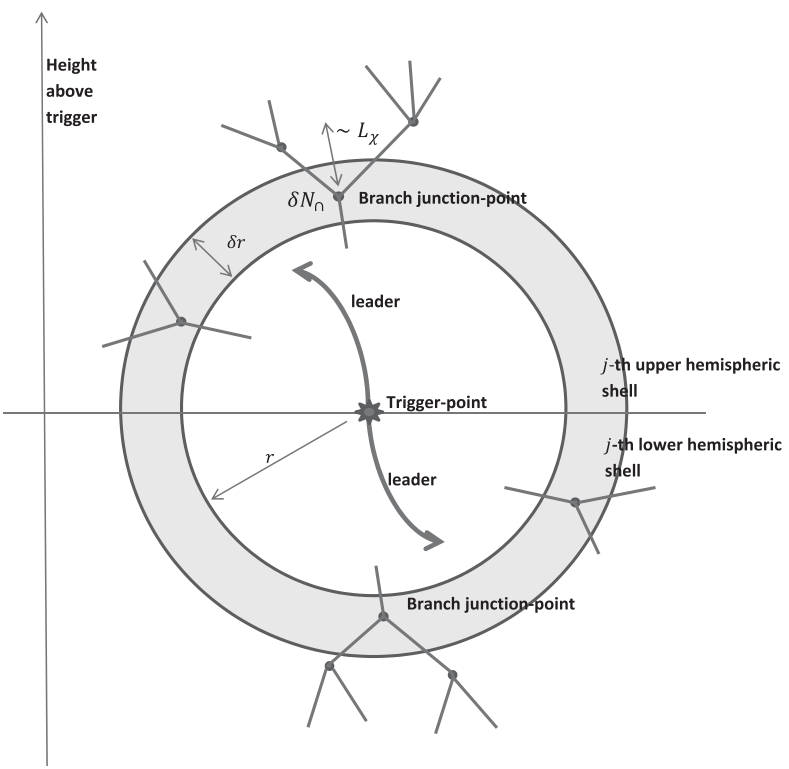

FIG. 1. Schematic diagram of the flashes branching algorithm as applied to a single flash. Two leaders propagate upward and downward from the trigger point. The branching volume around each leader is divided into many concentric hemispheric shells. Each hemispheric shell depicted here has a certain number of branches according to the number of its junction points.

$$
N=\left(\frac{r}{L_{\chi}}\right)^{\chi}
$$

In this fractal law $N$ is the number of junction points of branches $>0.5 \mathrm{~km}$ in the sphere of radius $r$ from the preflash trigger point while $L_{\chi}$ is a length scale. Figure 1 conveys the geometry of fractal branching schematically. The number of branch junction points of a polarity in the $j$ th hemispherical shell $(\delta r)$ of radius $r$ from the preflash trigger point is

$$
\begin{aligned}
\delta N_{\cap} \approx & \frac{\delta r}{2} \frac{d N}{d r}=\frac{\chi}{2}\left(\frac{1}{L_{\chi}}\right)^{\chi} r^{\chi-1} \delta \bar{L}=\frac{\chi}{2}\left(\frac{\delta \bar{L}}{L_{\chi}}\right)^{\chi} j^{\chi-1}, \\
N_{\text {grid }}(j) & =\kappa \times \delta N_{\cap},
\end{aligned}
$$

where $N_{\text {grid }}$ is the maximum number of grid boxes with branches in the shell; $\kappa$ is the number of grid boxes $(0.5 \mathrm{~km})$ per junction point of branches crossing them; $\delta r=\delta \bar{L}$, where $\delta \bar{L}$ is the diagonal gridbox width and $r=j \delta \bar{L}$. Equations (7) and (8) are unique. Appendix $\mathrm{C}$ implies $\kappa \approx 7\left(L_{\chi} / \delta \bar{L}\right)$. By cycling over all $j$ from the trigger, branched grid boxes of the leader are amassed.

For constants in (7), three composite images of lightning were taken from the Tall-Object Lightning Observatory in Guangzhou (TOLOG) in China with a high-speed video camera (Fig. 2). These were three downward -CGs both in and out of cloud, with upward leaders from tall structures. Junction points were counted for branches $>0.3 \mathrm{~km}$ in projected length (plane normal to view), corresponding on average to branches $>0.5 \mathrm{~km}$ in $3 \mathrm{D}$. Trigger points aloft were
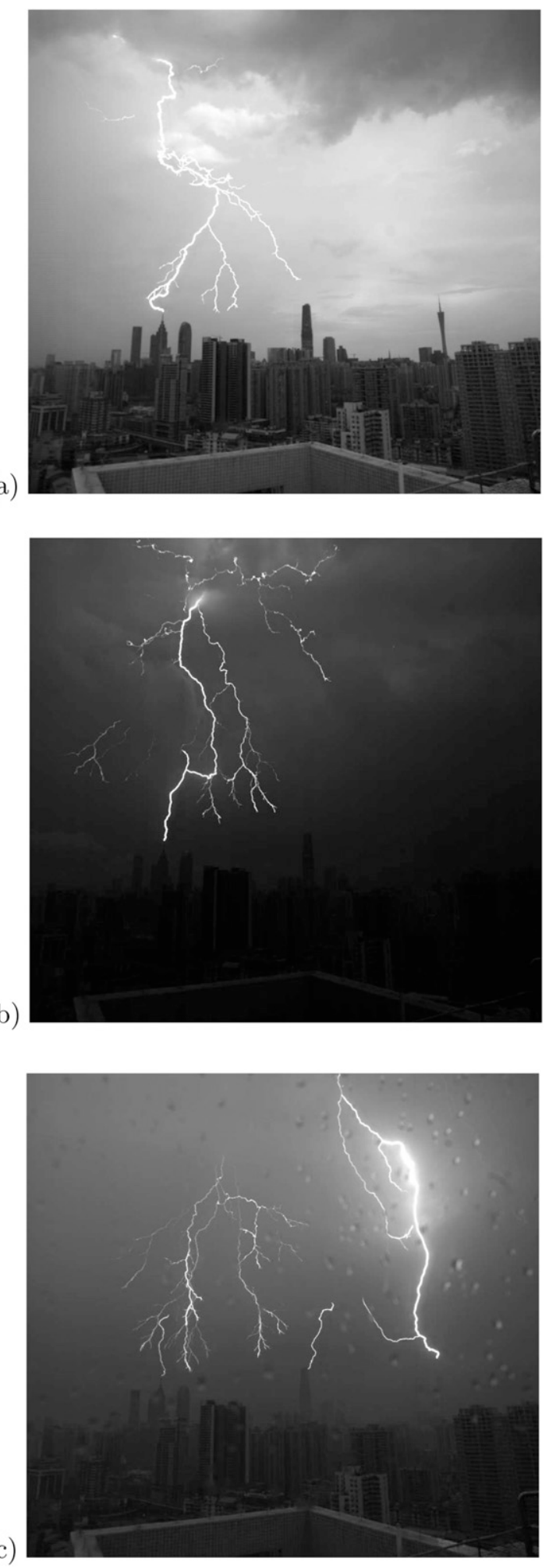

FIG. 2. Composite visible images of flashes to ground taken with a high-speed video camera from Guangzhou City in southern China, from (a) $22 \mathrm{Jul}$ and (b) 7 and (c) 24 Sep 2012. The resolution is 3 and $4.7 \mathrm{~m}$ per pixel and the distance to the striking point is 2.1 and $3.3 \mathrm{~km}$, for (a)/(b) and (c), respectively. These were all downward CGs, involving upward leaders from tall structures. 
assumed near $-10^{\circ} \mathrm{C}$ as typically observed there (Zheng et al. 2019). The mean for all three photos implies $L_{\chi} \approx 1.4 \pm 0.2 \mathrm{~km}$ ( $90 \%$ confidence interval, $t$ statistics).

\section{4) Neutralization of AMBIEnt CHARGE By LIGHTNING}

Ambient charge, on hydrometeors and air, is neutralized in each grid box of the flash as follows. The charge in the flash is $\rho_{\text {ch }}=\zeta\left|\rho_{q}-\rho_{\text {crit }}\right|$ where $\zeta=-\rho_{q} /\left|\rho_{q}\right|$ is the polarity of plasma with opposite sign to the net ambient space charge density, $\rho_{q}=\rho_{q, a}+\sum_{x} \rho_{q, x}$. Ambient space charge densities in air and in each $x$ th species, $\rho_{q, a}$ and $\rho_{q, x}$, are incremented by $\delta \rho_{q, a}=$ $\zeta \mathrm{MIN}\left(\left|\rho_{\mathrm{ch}}\right|,\left|\rho_{q, a}\right|\right)$ and $\delta \rho_{q, x}=\zeta \mathrm{MIN}\left(\left|\rho_{\mathrm{ch}}-\delta \rho_{q, a}\right|,\left|\rho_{q, x}\right| \chi_{x}\right)$, while $\chi_{x}$ is its fractional contribution to total hydrometeor surface area. Neutralization is incomplete in nature (Williams et al. 1985), as treated by $\rho_{\text {crit }}$. For ICs, $\delta \rho_{q, a}$ and $\delta \rho_{q, x}$ are normalized to have a total charge of zero over the flash, before altering $\rho_{q, a}$ and $\rho_{q, x}$. The normalization is not done for CGs as net charge in the flash after neutralization flows to ground.

\section{Description of observed case and model setup}

STEPS in summer 2000 observed convective storms by aircraft, balloons, radar, ground-based measurements, and satellite (Lang et al. 2004). The storm on 19/20 June had high cold cloud bases near $0^{\circ} \mathrm{C}(4.4 \mathrm{~km} \mathrm{MSL})$ at $3 \mathrm{~km}$ above ground $(1.3 \mathrm{~km} \mathrm{MSL})$. The case is representative of continental multicell storms in U.S. CGP (section 1) where cloud bases are usually colder than further south. It was a multicell system of convection $50-100 \mathrm{~km}$ wide.

The storm began over Colorado at about 2200 UTC (1600 local time) and moved almost eastward (about $70^{\circ}$ from north). Graupel $(<0.5 \mathrm{~cm})$ and snow were ubiquitous in aircraft observations. During flights, small hail $(>0.5 \mathrm{~cm})$ was detected, especially on flanks of convective updrafts (Goehring 2005; Phillips et al. 2017b). Convective cells (reflectivities up to $55 \mathrm{~dB} Z$ aloft) coexisted with a lightly precipitating stratiform cloud deck (about $20 \mathrm{dBZ}$ ).

The multicellular storm is simulated in a $3 \mathrm{D}$ domain $(80 \mathrm{~km} \times 80 \mathrm{~km} \times 16 \mathrm{~km})$, approximating it as a convective line with cells initiated at $x=30 \mathrm{~km}$. Translation of the domain keeps them in it. The horizontal $x$ axis points $70^{\circ}$ from north. Phillips et al. (2017b) elaborate further.

\section{Results from model validation}

Regarding nonelectrical quantities, Phillips et al. (2017b, their Figs. 5 and 6) showed agreement between the AC simulation of the STEPS case (1145 UTC 19 June-0215 UTC 20 June 2000; section 3) and coincident observations by aircraft, satellite, and ground-based instruments for many quantities. Vertical profiles of mean diameter and concentration of droplets, LWC, radar reflectivity, filtered ice concentration, and PSDs were among quantities predicted accurately. Predicted and observed concentrations of ice particles $(>0.2 \mathrm{~mm})$ identically averaged in convective updrafts were on the order of $10 \mathrm{~L}^{-1}$ at flight levels. Differences between prediction and observations were less than the spread of observations.

With electrification represented, Fig. 3 compares predicted and observed flash rates (Tessendorf et al. 2007) and ascent
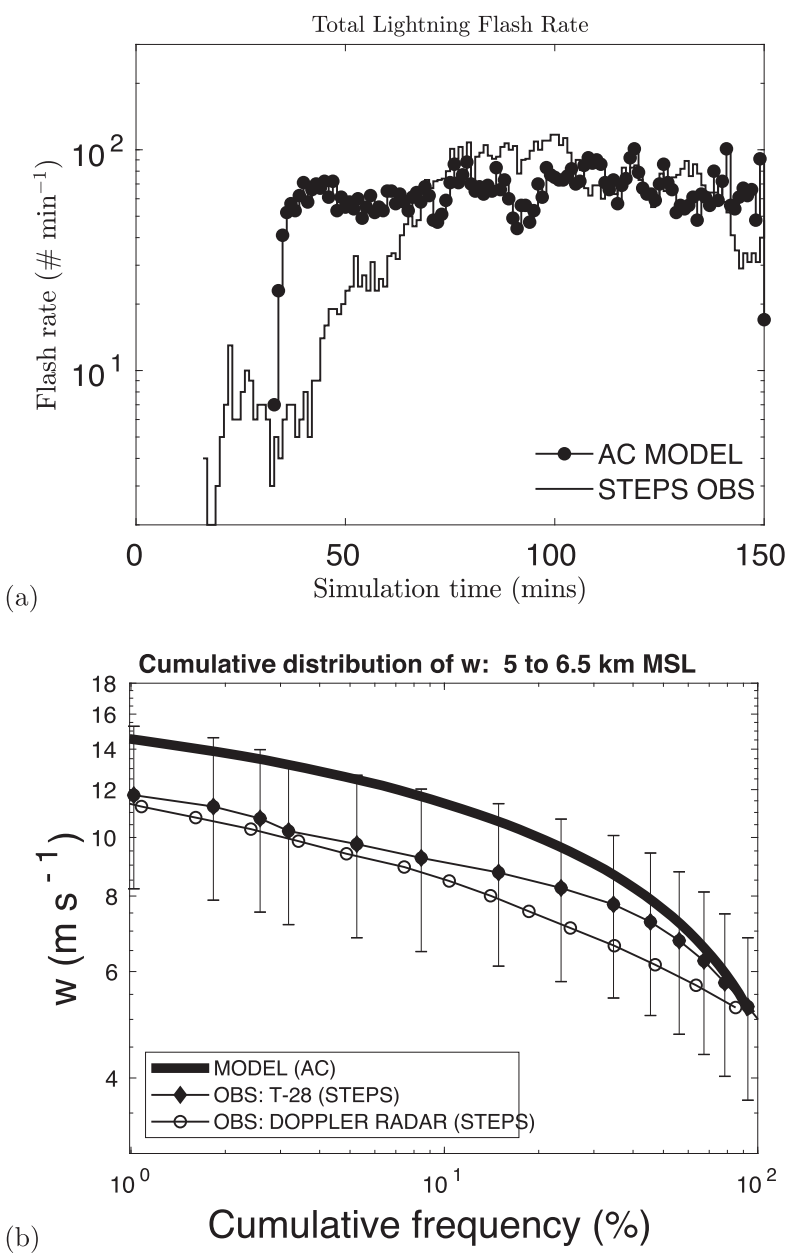

FIG. 3. (a) The total flash rate in the simulated domain, predicted (closed circles) and observed (thin line) for the STEPS case (2345 UTC 19 Jun-0215 UTC 20 Jun 2000). Lightning data observed by LMA were computed on a moving grid that followed the model domain (Phillips et al. 2017b). Also shown is (b) the cumulative distribution of vertical velocity between 5 and $6.5 \mathrm{~km}$ MSL in fast convective updrafts $>5 \mathrm{~m} \mathrm{~s}^{-1}$, comparing the prediction (thick line) with observations by aircraft and Doppler radar (lines with symbols). Transient fluctuations of up to about $3 \mathrm{~m} \mathrm{~s}^{-1}$ arose from flight maneuvers, so the relative error in aircraft data of ascent is assumed to be $\pm 30 \%$.

statistics at flight levels of 6-7 km MSL. The flash rate is simulated with errors mostly less than a factor of 2 . Aircraft data of ascent are more accurate than the radar data and agree with the predicted ascent at all cumulative frequencies of vertical velocity. Dual-Doppler ascent retrievals have wide biases (Dahl et al. 2019).

Figure 4 depicts numbers of all flashes. Most ( $>99 \%$ ) are IC, the rest $(1 \%)-\mathrm{CG}$. Model and observations agree, differing by about $10 \%$. A few (4\%) observed CGs were apparently $+\mathrm{CG}$ as predicted, though misclassification of ICs as +CGs is possible (Cummins et al. 1998; Leal et al. 2019). The IC/CG ratio of $10^{2}$ is large (Lang et al. 2000; Williams 2001; Boccippio et al. 2001). A high cloud base 


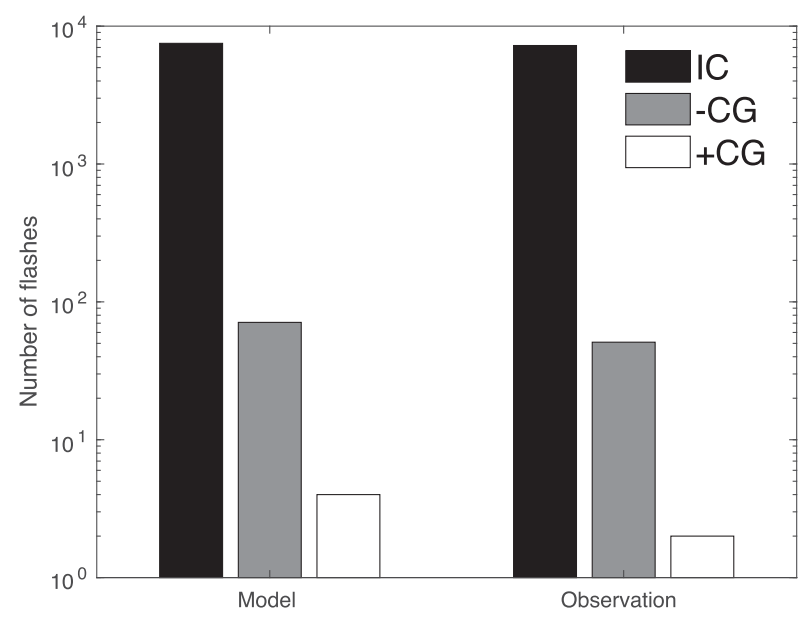

FIG. 4. Observed and simulated (AC) total numbers of flashes for the three types of lightning in the STEPS case (23450215 UTC), namely, intracloud (IC; black), negative cloud-toground ( $-\mathrm{CG}$; gray), and positive cloud-to-ground (+CG; white) lightning. For observed flashes, only those in the 3D domain simulated (Phillips et al. 2017b, their Fig. 1a) are counted.

(3 km above ground) from a dry lower troposphere inhibited charged surface precipitation and hence CGs, for reasons noted below.

Figure 5 shows - CGs and estimated altitudes of trigger points. Observations and predictions agree in timing and frequency. Most - CGs were initiated in convective cloud near $6-7 \mathrm{~km} \mathrm{MSL}\left(-10^{\circ}\right.$ to $\left.-17^{\circ} \mathrm{C}\right)$, in the lower half of the central negatively charged region (5.5-9 km MSL) of the large-scale tripole. Heights of triggering for all flashes are predicted adequately, but with a peak $2 \mathrm{~km}$ too high (Fig. 5b). Observed and predicted ICs were mostly initiated at 6-9 MSL altitude (about $-10^{\circ}$ to $-30^{\circ} \mathrm{C}$ ) with a peak near $8 \mathrm{~km}$ MSL (about $-25^{\circ} \mathrm{C}$ ). They were predicted to arise often from intense charge of transient graupel/hail fall shafts in convective cells, at levels in the midst of the central negative region of the large-scale tripole. A few flashes $(10 \%)$ were observed to trigger at $3-5 \mathrm{~km}$ MSL, especially ICs at $4.4-5 \mathrm{~km} \mathrm{MSL}\left(0^{\circ}\right.$ to $-4^{\circ} \mathrm{C} ; 0110$ to $\left.0200 \mathrm{UTC}\right)$, levels where none are predicted (section 6).

Timing of $-\mathrm{CGs}$ is explicable in terms of surface precipitation (Fig. 5a). Predicted accumulation of charge in surface precipitation from similarly charged graupel causes that of opposite charge to ground from CGs (section 5b), as with all simulations in Part II (not shown), leading it by 10-20 mins, because removal of charge in precipitation creates the total storm charge aloft. In normal (inverted) storms, AC predicts net transfer of positive (negative) charge to the surface in precipitation and then $-\mathrm{CGs}(+\mathrm{CGs})$ as a lagged response in all simulations. As most - CGs or + CGs originate from midlevels and conduct negative or positive charge toward the higher or lower potential of the ground (always zero volts), respectively, they respond to the total of all net charge and average potential of the entire convective core caused by fallout of oppositely charged precipitation to ground. This is
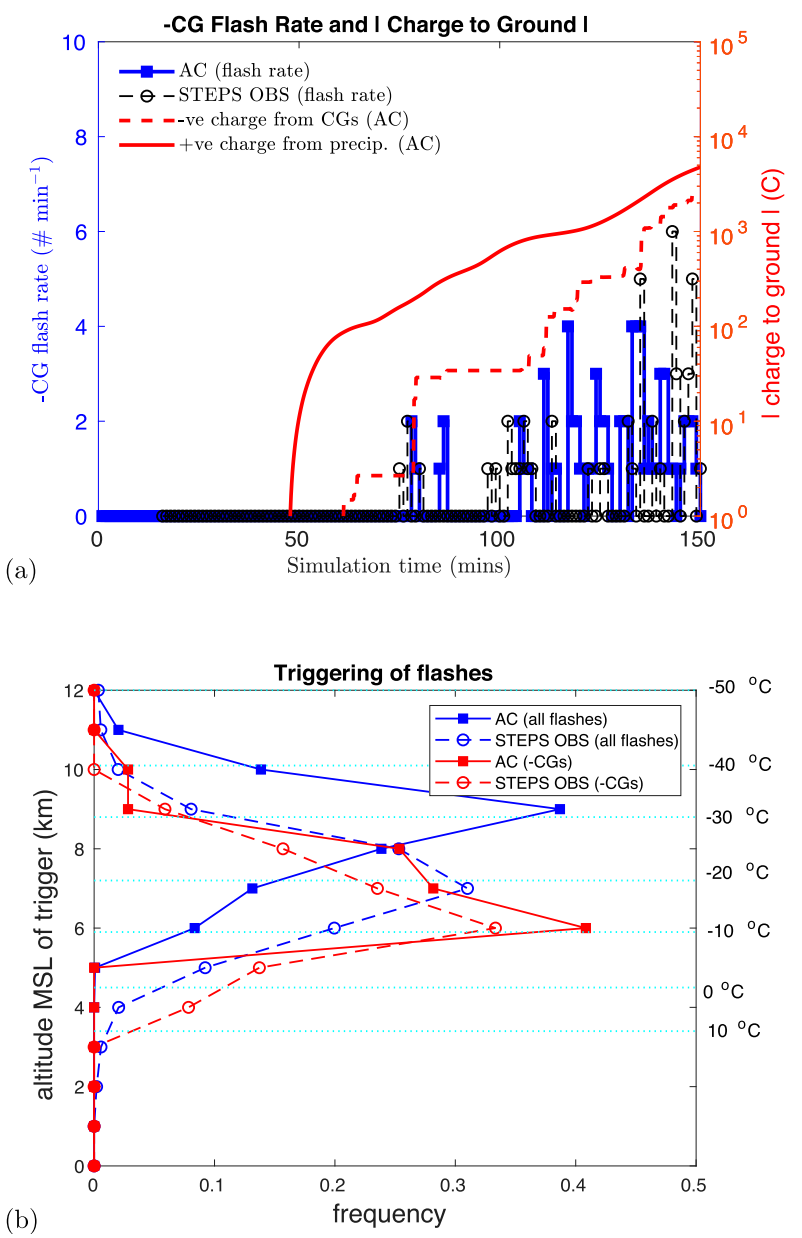

FIG. 5. Negative cloud-to-ground flashes for the STEPS case (2345-0215 UTC), observed (open symbols) and predicted by AC (closed symbols). (a) Their time evolution in terms of numbers of -CGs every minute (black and blue lines). (b) The vertical profile of relative frequencies of their estimated trigger-point altitude. Also shown in (b) is the corresponding vertical profile for all flashes, the vast majority of which are IC. Finally, superimposed in (a) is the time evolution of accumulated absolute magnitude of charge at the ground (red lines) from precipitation (positive) and CGs (negative).

why arrival of surface precipitation in the second half of the simulation (Phillips et al. 2017b, their Fig. 5) coincides with -CGs. Generally, onsets of CGs and surface precipitation are observed to coincide to within a few mins (Gungle and Krider 2006) with CG number controlled by rainfall volume (Battan 1965; Kinzer 1974; Piepgrass et al. 1982). Here, to summarize, positive charge of surface precipitation causes negative average charge on the simulated normal storm and - CGs as a response. Corona discharge may complicate this picture (section 6). Equally, charged precipitation shafts below cloud promote propagation of CGs downward.

Number density of LMA sources (VHF) was observed in STEPS. They have no polarity, but the negative end of a flash produces more sources (e.g., Dwyer et al. 2004, 2005) than the 


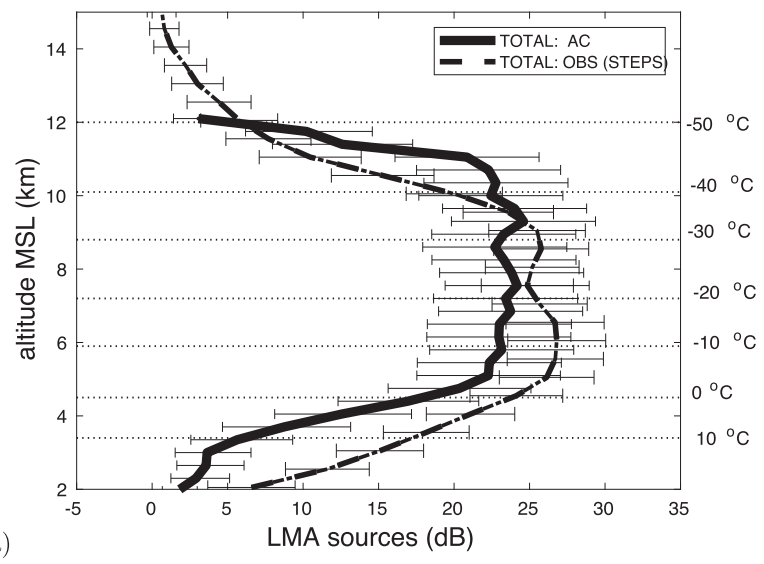

(a)

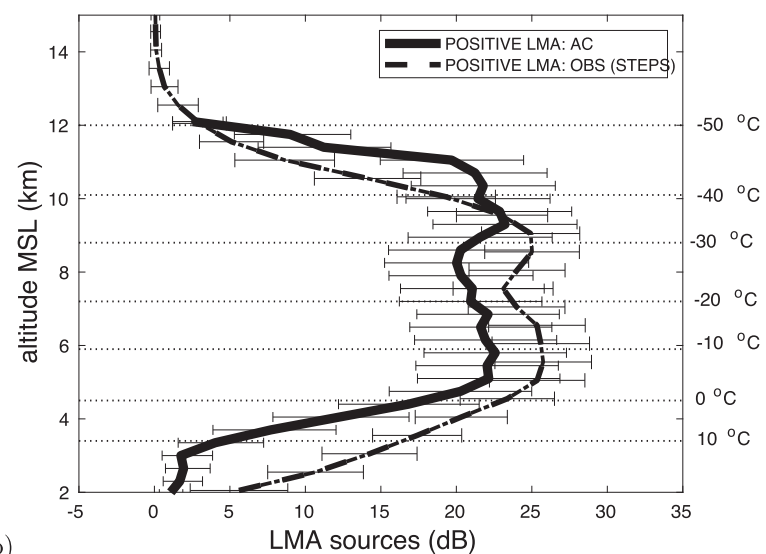

(b)

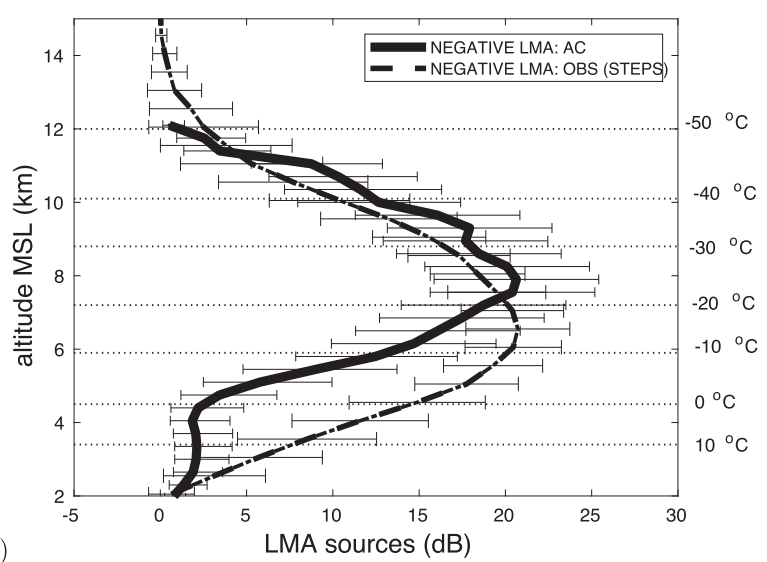

FIG. 6. The density of (a) all LMA sources expressed in decibels $\left(\mathrm{dB} ; 10 \log _{10}[\right.$ number of average sources per min per volume element $\left(\mathrm{min}^{-1}\right)$ ]) for the AC simulation (2345-0215 UTC) (thick full line) and STEPS observations from the region $(80 \mathrm{~km} \times 80 \mathrm{~km})$ simulated (dashed line). In both observations and simulation, the $3 \mathrm{D}$ domain is divided into volume elements $0.5 \mathrm{~km}$ deep and $10 \mathrm{~km}$ wide in one horizontal direction, spanning the domain in the other, with averaging over all elements at each level (Wiens et al. 2005). The source profiles in $\mathrm{dB}$ for every minute are then averaged over the simulated period. Corresponding contributions from (b) positive (negative breakdown through ambient other end, so polarity of ambient volume can be inferred. For comparison, this source density is diagnosed from AC output by assuming proportionality with charge neutralized in each grid box, a novel method. The constant of proportionality gives observed numbers $\left(\sim 10^{3}\right)$ of sources per flash for storms generally (Wiens et al. 2005). The constant $\left(200\right.$ or $\left.50 \mathrm{nC}^{-1}\right)$ is 4 times higher for "positive LMA" sources (negative breakdown through ambient positive charge) than negative sources (vice versa), as seen in storms by Wiens et al. (2005), Rison et al. (1999) and the case here.

Figure 6 shows agreement between predicted and observed profiles of total, positive and negative LMA sources for cloudy levels (4-13 km MSL). There are deep broad maxima for all and positive sources near 25 and $23 \mathrm{~dB}$, respectively, over 5$10 \mathrm{~km}$ MSL (about $-5^{\circ}$ to $-40^{\circ} \mathrm{C}$ ) and a narrower peak of negative sources of about $20 \mathrm{~dB}$. Predicted negative LMA sources are about $1 \mathrm{~km}$ too high, consistent with ICs being triggered at levels too high also.

Figure 7 shows horizontal distance of predicted trigger points from maximum ascent $\left(13 \pm 4 \mathrm{~m} \mathrm{~s}^{-1}\right)$ in the nearest convective core. Most (97\%) are in the core. About $3 \%$ are in stratiform/cirriform cloud, being triggered "remotely," $10-20 \mathrm{~km}$ from the core's maximum ascent, with a few (0.02\% ) 18-20 km away. A compass plot shows simulated trigger points in the horizontal plane relative to the nearest core (Fig. 7b). Favored locations of remote trigger points $(>10 \mathrm{~km})$ are between adjacent cells where electric fields superpose. Triggering here slightly prefers sides of any cell that are upshear and to the left of the system's propagation direction, because the environmental vertical shear is not unidirectional.

Most charging of graupel occurs in convective ascent (section 5b). Yet broad continua of sizes and fall speeds of graupel in any cloudy volume create vertical charge structure in the layer cloud from outflow, causing a continuous distribution of horizontal distances of triggering from the core (by up to $20 \mathrm{~km}$ away here). The prediction (Fig. 7) accords with observations of most lightning being triggered in cores and with a few flashes triggered tens of kilometers away (Proctor 1991; Wiens et al. 2005; Dye and Willett 2007; Weiss et al. 2012; Kuhlman et al. 2009). Supercooled cloud liquid must be present for any charge separation to occur in AC.

In the STEPS case, electrical properties of the storm were measured by balloon. Figure 8 shows the balloon trajectory, initially $20 \mathrm{~km}$ downshear of convection $(<50 \mathrm{dBZ})$ in weak reflectivity (about $0 \mathrm{~dB} Z$ ). Struck by lightning at $9 \mathrm{~km} \mathrm{MSL}$, all other flashes around it were triggered at least $5 \mathrm{~km}$ away (Fig. 8). The balloon rose through layer cloud toward the

positive charge) and (c) negative (vice versa) LMA sources are compared similarly. Errors of the prediction arise from choice of average value of LMA sources per flash (about 1000), which may vary by about half an order of magnitude (e.g., Wiens et al. 2005). The error shown for the observed profile is the standard deviation for the variability over time. For simplicity, the observations were analyzed over a fixed domain of the same size as the model. 

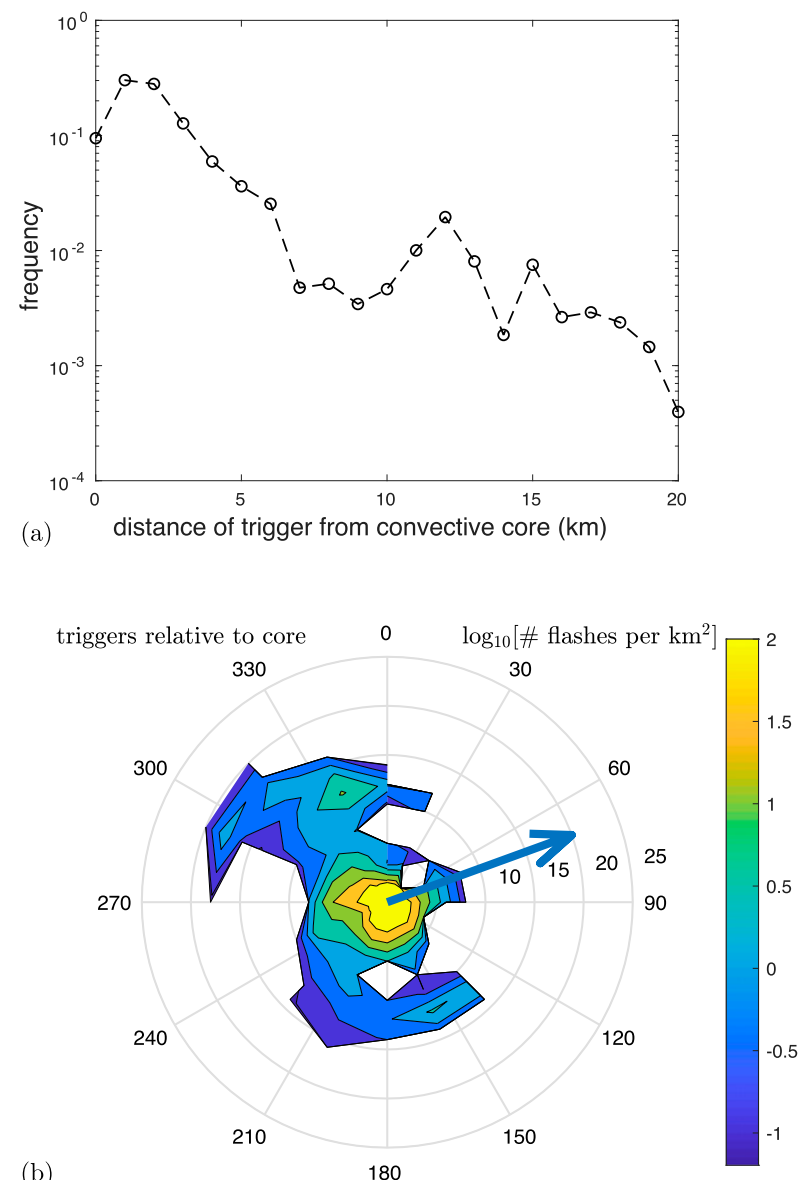

FIG. 7. From the AC simulation are shown (a) relative frequency of the horizontal distance of the trigger points from the center of the nearest convective core for all flashes of the STEPS case (23450215 UTC) and (b) their relative positions compared to this composite core in terms of flash density (logarithm of number per $\mathrm{km}^{2}$ ) in the horizontal plane. The vast majority are IC. In (b), the origin of the compass plot is the axis of the strong convective updraft nearest to each trigger and the blue arrow delineates the direction of storm propagation. Angles in (b) are directions defined clockwise from north while distances are in $\mathrm{km}$.

downshear anvil of approaching cells, missing them (Goehring 2005, Fig. 26 therein).

Figure 9 compares quantities measured by balloon and simulated for an ensemble (30) of virtual balloon trajectories. The AC simulation is idealized and cannot reproduce positions of real clouds. From AC output, each trajectory was traced, ascending $7 \mathrm{~m} \mathrm{~s}^{-1}$ faster than the evolving wind to match observed altitudes. Trajectories were initiated randomly from a square $(10 \mathrm{~km})$ about $10 \mathrm{~km}$ east of a cell with a similar reflectivity to that near the real balloon. The predicted mean electric field (Fig. 9a) agrees with the observations. The maximum measured was $30 \mathrm{kV} \mathrm{m}^{-1}$ ( $\left.8 \mathrm{~km} \mathrm{MSL}\right)$, much weaker than the breakdown threshold $\left(90 \mathrm{kV} \mathrm{m}^{-1}\right)$. The balloon sampled large-scale conditions ahead of the convective line.

Total space charge density, $\rho_{q}$, is from the balloon sounding using $d E_{z} / d z \approx \rho_{q} / \epsilon$, where $E_{z}$ is the vertical component of E. Figure 9b compares it with AC's ensemble. A normal tripolar charge structure (e.g., Williams 1989) is predicted and observed:

- weak positive charge below the $-10^{\circ} \mathrm{C}(6 \mathrm{~km} \mathrm{MSL})$ level;

- strong negative charge at $6.5-8 \mathrm{~km} \mathrm{MSL}$ (about $-15^{\circ}$ to $-25^{\circ} \mathrm{C}$ );

- moderate positive charge at $8-10 \mathrm{~km}$ MSL (about $-25^{\circ}$ to $-38^{\circ} \mathrm{C}$ ) aloft.

Normal tripoles are associated with predominance of -CGs among strikes to ground, as in the simulation. Most-CGs were triggered at lower levels of this central negative region, where negatively charged snow remains as graupel/hail falls out. The normal tripole is here predicted for reasons (central negative charge due to snow/crystals, rather than graupel) differing from the traditional explanation of normal tripoles (Williams 1989) (section 5a).

Figure 10 compares predicted charge to ground in -CGs with that inferred from peak currents (Rakov and Uman 2003; Schoene et al. 2010) observed in STEPS. They agree in terms of both the median charge per flash and the statistical distribution among all flashes to ground.

\section{Results for other electrical quantities of STEPS case}

\section{a. Spatial distribution of predicted charge and electric field}

Figure 11 shows space charge density averaged over the domain. Features seen in the balloon sounding (Fig. 9) are evident. The most intense charges are on graupel (positive) and snow (negative). The net charge in the storm is from differential sedimentation of graupel versus snow/crystals. Most charge on graupel is from rebounding collisions with (cloud-ice) crystals, the process observed by Takahashi (1978) (section $2 \mathrm{~b}$ ). Once charged, many crystals grow to become charged snow. Fluctuations of LWC below average are the cause of graupel mostly charging positively (section $5 b$ ), as noted below.

The normal tripole in Fig. 11 is explicable as follows. First, at midlevels below $10 \mathrm{~km}$ MSL (about $-38^{\circ} \mathrm{C}$ ), the averaging includes regions of negative and positive charge on graupel in extreme (rich LWC) and moderate/weak (low LWC) convective ascent, respectively. Weaker ascent is wider and prevails, so graupel charges mostly positively. Above $8-9 \mathrm{~km}$ MSL (near $-30^{\circ} \mathrm{C}$ ) the polarity of both oppositely charged ice species dominating charging (graupel and cloud-ice crystals) in Fig. 11 reverses, as in the laboratory data of charging (Takahashi 1978, his Fig. 8). In the laboratory the rimer was seen to charge negatively at LWCs $>0.1 \mathrm{~g} \mathrm{~m}^{-3}$ if $T<-30^{\circ} \mathrm{C}$, but always positively if $T>-10^{\circ} \mathrm{C}$ (section $5 \mathrm{~b}$ ). Graupel in the fastest ascent $\left(\mathrm{LWC} \sim 1 \mathrm{~g} \mathrm{~m}^{-3}\right.$ ) becomes negatively charged when $T<-15^{\circ} \mathrm{C}$, being upwelled into cirriform outflow aloft. Conversely, graupel in moderate/weak convective ascent charges positively and likely remains at lower levels, detraining into stratiform cloud.

Net charge in narrow graupel/hail shafts $(6-8 \mathrm{~km}$ MSL; $-10^{\circ}$ to $-25^{\circ} \mathrm{C}$ ) is predicted to be mostly positive. This agrees with LMA observations of net charge being positive at midlevels (6-8 km MSL) in a graupel/hail shaft ( $45 \mathrm{dBZ})$ next to an updraft $\left(>5 \mathrm{~m} \mathrm{~s}^{-1}\right)$ from Tessendorf et al. (2007, 


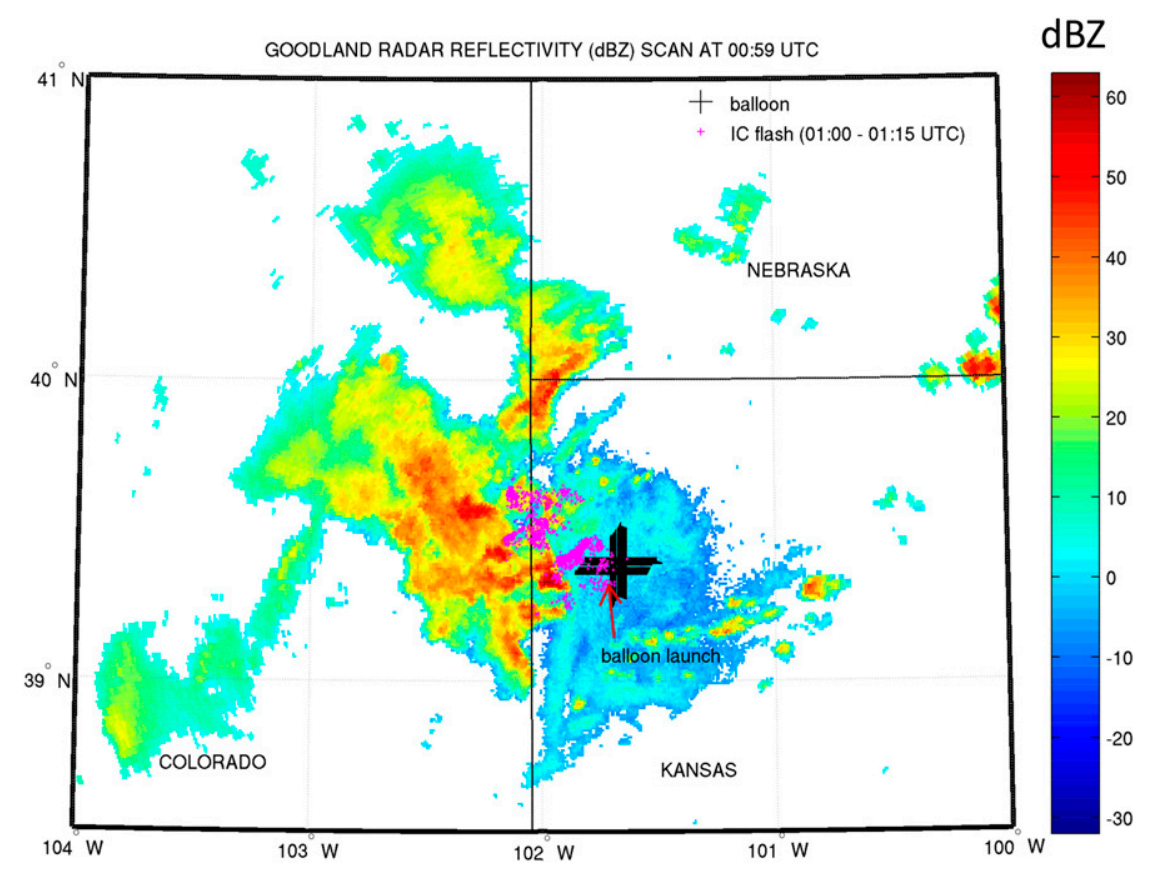

FIG. 8. Plan view of balloon trajectory (large black plus symbols) superimposed on a $0.48^{\circ}$ elevation angle scan of equivalent reflectivity factor $(\mathrm{dBZ})$ near the ground from the Goodland radar at the moment of release (0059 UTC 20 Jun 2000). The balloon is almost $20 \mathrm{~km}$ to the east of a reflectivity maximum of about $40 \mathrm{dBZ}$ when launched and then drifts several kilometers northeastward. Also shown are the IC flash trigger points (magenta tiny plus symbols) during ascent of the balloon until it was struck by lightning at $9 \mathrm{~km}$ MSL altitude. The balloon was launched by the National Severe Storms Laboratory (NSSL) from Goodland airport.

their Figs. 12c,d, their $x=-68 \mathrm{~km}$ ) in this STEPS case at 0019 UTC. In stratiform outflow (30-40 dBZ) from this updraft (0019 UTC), observed LMA sources are negative at midlevels. Positivity of graupel/hail shafts is observed to coexist with average negativity on the large scale $(>5 \mathrm{~km})$, as in the simulation.

In Fig. 11, at upper levels predicted net charge (positive above $9 \mathrm{~km} \mathrm{MSL}$ ) is caused by cloud-ice crystals, which are spread by their slow fall speeds coupled with large stormrelative flow over wide areas. Positivity of cloud ice and negativity of graupel are due to charge reversal in the laboratory data, as noted above. At lower levels (5 km MSL), weak positive net charge is from positively charged graupel falling out.

Comparing Figs. 5, 6, and 11 reveals that -CGs, simulated and observed, originate from intense electric fields between the strong central negative and low-level positive centers of the large-scale tripole. ICs originate from most subzero levels, but especially in the upper half $\left(-20^{\circ}\right.$ to $-30^{\circ} \mathrm{C}$ ) of the central negative region of the large-scale tripole. ICs are often triggered near transient narrow shafts of intensely charged graupel/hail (see snapshots below).

Figures 12 and 13 show snapshots of electrical and microphysical quantities in vertical sections where lightning was triggered in a cell at 0055 UTC. Peak updraft speed is $15 \mathrm{~m} \mathrm{~s}^{-1}$ with $\mathrm{LWC}<2 \mathrm{~g} \mathrm{~m}^{-3}$. Supercooled liquid is confined to the convective updraft ( $5 \mathrm{~km}$ wide) below the $-20^{\circ} \mathrm{C}$ level, while cirriform and stratiform cloud is ice-only (Figs. 13a,b) due to weakness of ascent (Korolev 2007). Both charging and graupel production (Figs. 12a,d and 13b,e,f) coincide in the cell. Graupel forms near updraft edges from riming of snow (Figs. 13d,e). Collisions between graupel and secondary cloud-ice crystals cause the charging.

A shaft of positively charged graupel falls from the downshear (eastern) side of the cell, leaving negatively charged snow/cloud ice aloft (Figs. 12b-d). Near $10 \mathrm{~km}$ MSL there is a widespread upper-level layer of positively charged snow/cloud ice. Deep positive charge on graupel typifies the Takahashi charging scheme: in extreme ascent $\left(>15 \mathrm{~m} \mathrm{~s}^{-1}\right)$ supercooled liquid is sufficient (e.g., $1 \mathrm{~g} \mathrm{~m}^{-3}$ ) for graupel to charge negatively. Slightly negatively charged graupel (Fig. 12d) extends downshear from the cell near $10 \mathrm{~km} \mathrm{MSL,}$ capping the positively charged graupel shaft below. Offline tracing of back trajectories of positively $(z=6.5 \mathrm{~km} \mathrm{MSL}$, $x=32 \mathrm{~km})$ and negatively $(z=8.5 \mathrm{~km} \mathrm{MSL}, x=27.5 \mathrm{~km})$ charged graupel confirm

- negatively charged graupel is from ascent $>15 \mathrm{~m} \mathrm{~s}^{-1}$ ( $\mathrm{LWC}>1 \mathrm{~g} \mathrm{~m}^{-3},-10^{\circ}$ to $-30^{\circ} \mathrm{C}$ ) and

- positively charged graupel originates from weaker ascent (e.g., $<3 \mathrm{~m} \mathrm{~s}^{-1}$ ) with $\mathrm{LWC}<0.3 \mathrm{~g} \mathrm{~m}^{-3}$ at warmer levels $\left(>-12^{\circ} \mathrm{C}\right)$.

In much of the narrow shaft, the net space charge has the same sign as the charge on graupel/hail (Figs. 12a,b). Three ICs in 


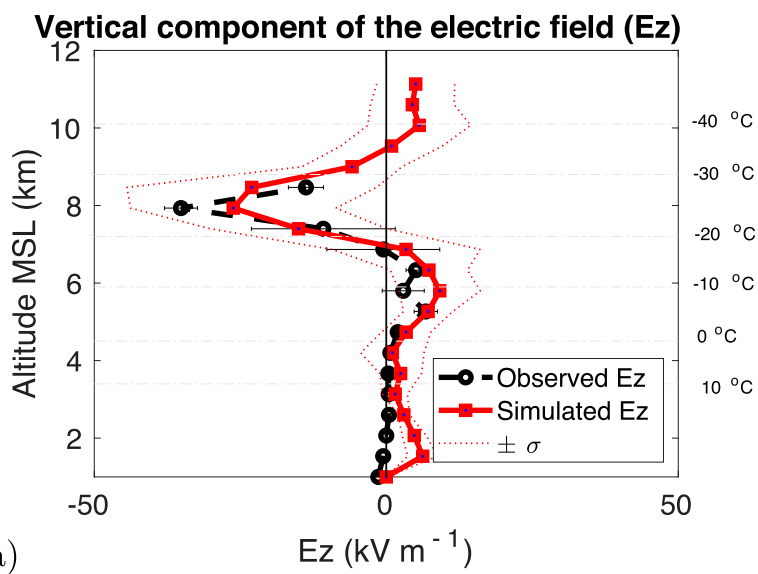

(a)

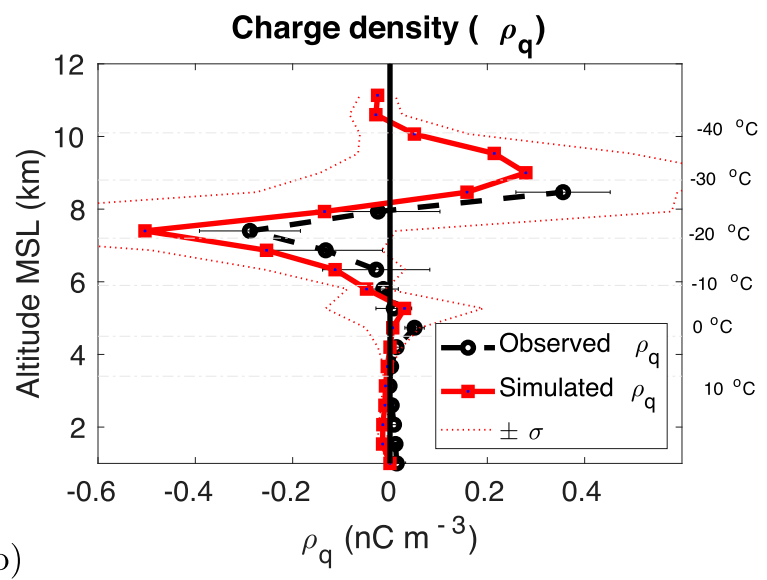

FIG. 9. (a) The vertical component of electric field (Ez) both observed (black open symbols) and predicted by AC (red closed symbols). Measurements were from an electric field meter on the balloon plotted in Fig. 8. The full line of the model is the mean of an ensemble of many possible simulated trajectories of the balloon. Positive values indicate an upward electric field. (b) A vertical profile of the inferred net charge density from the same balloon observations (black open symbols) compared with the average for the ensemble of simulated trajectories (red closed symbols). Both model and observations depict the large-scale normal tripole of charge structure. Errors plotted in (a) and (b) are standard deviations (thin dotted lines and error bars), to depict the spatial variability. Observational points $(1 \mathrm{~s})$ of electric field were binned in layers, with the standard deviation shown for each bin in (a) and determining that of inferred charge density for error bars in (b).

Fig. 12 are triggered near 7 and $10 \mathrm{~km} \mathrm{MSL}$ by its strong electric fields. They are triggered between adjacent oppositely charged regions of the shaft dominated by graupel and snow/ cloud ice, respectively. Such transient graupel/hail shafts and sensitivity of the charging scheme to $T$ or LWC govern locations of triggering.

Throughout the storm the net charge density typically involves

- an intense narrow normal tripole in each convective cell due to a graupel shaft at midlevels with net positive charge (on

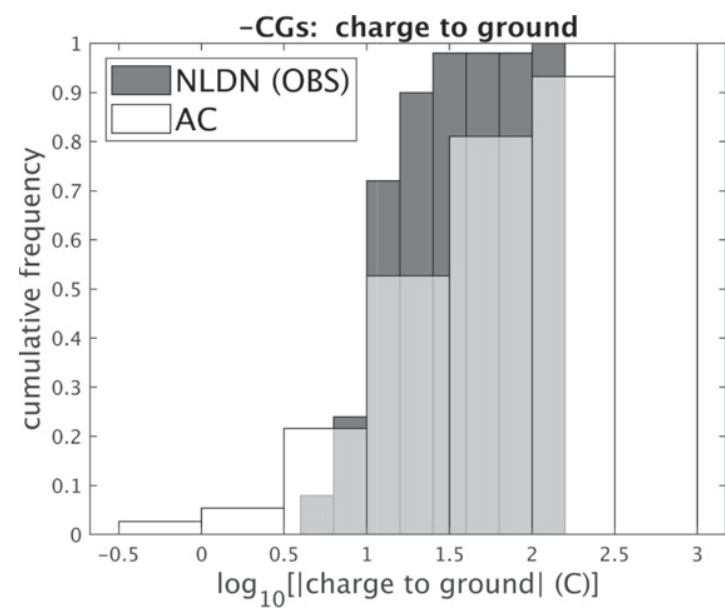

(a)

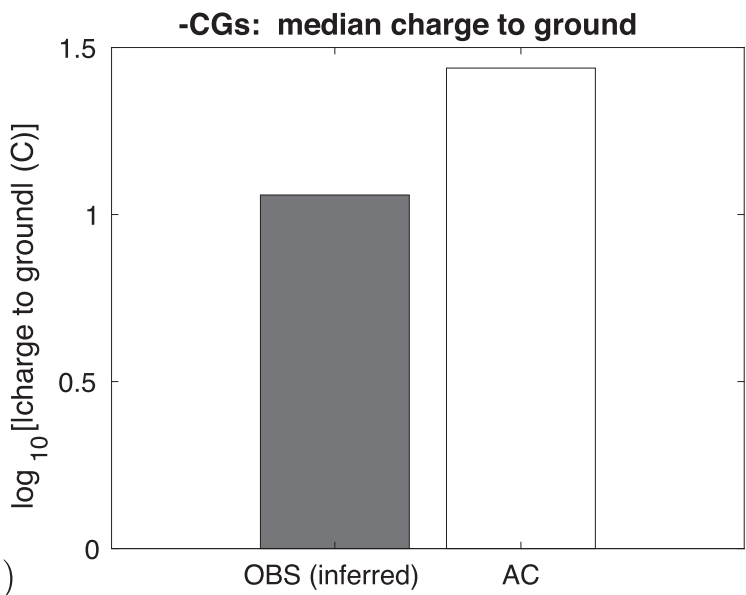

FIG. 10. Observed ("NLDN") and predicted ("AC") amounts of negative charge in any flash to ground among all -CGs in the simulated region of STEPS. The logarithm of the absolute magnitude of the charge transferred to ground is shown. The -CG flashes are the same set shown in Fig. 4. Charge was inferred from NLDN observations of peak current by assuming proportionality to the square of the peak current in view of empirical relations for rocket-induced artificial lightning by Schoene et al. (2010, their Fig. 4). The constant of proportionality was constrained by general known characteristics of -CGs from Rakov and Uman (2003, their Table 1.1) showing about $30 \mathrm{C}$ (30\% error) typically transferred for a peak current of $30 \mathrm{kA}$. The error in observed charge is about half an order of magnitude, partly due to variability of the exponent (2) among the empirical relations.

graupel) next to negative charge (on snow/cloud ice), capped by upper-level positive charge on cloud ice;

- a weak, widespread normal dipole in layer cloud extending tens of kilometers downshear, with slight net negative (on graupel) charge below positive (on snow/crystals) charge.

The intense narrow tripole has electric fields $>50 \mathrm{kV} \mathrm{m}^{-1}$ near breakdown and reflectivities of $35-40 \mathrm{~dB} Z$. The widespread dipole has fields $<30 \mathrm{kV} \mathrm{m}^{-1}$ and a reflectivity of $20-30 \mathrm{~dB} Z$.

Figure 14 schematically illustrates a conceptual model of how the lightning occurs. It shows the dynamics of charged ice (orange arrows for snow/crystals; green arrows for graupel) 


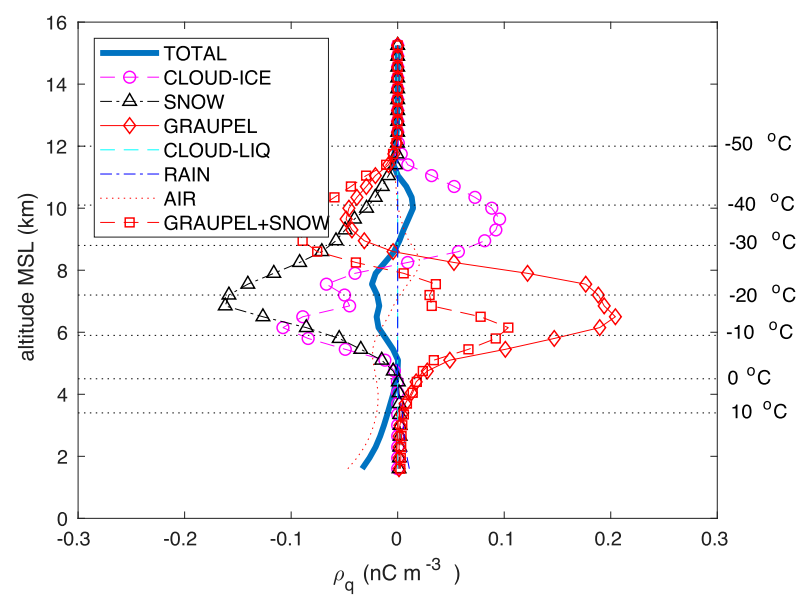

FIG. 11. Unconditional averages from the STEPS simulation by AC over the entire domain of total space charge density (thick full line) and its components from cloud ice, snow, and graupel (thin lines with symbols). Charge densities in air and on rain are shown (thin dotted and dot-dashed lines). The net charge on cloud liquid is negligible.

for a convective cell with outflow to stratiform/cirriform cloud. The central net negative charge $\left(-10^{\circ}\right.$ to $\left.-25^{\circ} \mathrm{C}\right)$ of the intense normal tripole is created by positively charged graupel falling out to leave negative charge on snow/cloud ice aloft. Almost all charging happens in the cell, with little liquid elsewhere. Upper-level positivity of anvil cloud ice arises from charge reversal in the fastest ascent and colder subzero temperatures (red ellipse in Fig. 14), as seen in the laboratory (Takahashi 1978) (section 5b). Each ice-microphysical species displays both signs of charge in Fig. 12, as observed (Takahashi et al. 2017). The weak widespread normal dipole in the layer cloud is due to horizontal advection of slightly positive (snow/cloud ice aloft) and negative (graupel) charge from convective outflow at upper levels (Fig. 14). The picture is consistent with radar data from Tessendorf et al. (2007, their Fig. 12d). The balloon (curved line) missed the intense tripole of the shaft, rising in the widespread normal dipole.

This picture contrasts with the traditional explanation of the intense normal tripole in terms of negatively charged graupel causing the central negative region and separating from positive snow/cloud ice upwelled into the anvil (Williams 1989). Yet our picture accords with simulations by Barthe and Pinty (2007) and Barthe et al. (2012) of net positive charge at lower levels from positively charged graupel/hail falling out. Hail below most thunderstorms is observed to be positively charged as noted above (section 2; e.g., Rust and Moore 1974), causing the lower positive charge of the normal tripole (Jayaratne and Saunders 1984). Our picture involves graupel/hail dominating net charge only in the lower positive charge center of the large-scale tripole, with central and upper charge centers dominated by crystals/snow. The upper positive charge is from reversed polarity of charging (section 5b).

Figure 15 shows evolution over time of charge and contents of hydrometeors averaged over the domain. Observed surface precipitation is appreciable only during the final half hour of the simulation (Phillips et al. 2017b), when most CGs were observed. The simulation finishes before the storm decays. Similarly, the observed lightning flash rate remains high beyond the simulated period (Fig. 3). The AC simulation is idealized with a domain following the storm and a quasi-steady state dynamically. No attempt is made to simulate the storm's decay, which would require relaxation of heat and moisture at inflow boundaries.

During the simulation the ice concentration in the mixedphase region (Fig. 15a) explodes almost exponentially from multiplication involving fragments from graupel-snow collisions growing to become snow and fragmenting. It reaches about 10 and $30 \mathrm{~L}^{-1}$ after the first and second hours at $8 \mathrm{~km}$ MSL respectively, one or two orders of magnitude higher than primary ice as observed (Phillips et al. 2017b, their Fig. 5d). The normal large-scale tripole persists (Fig. 15f), but becomes an inverted dipole in the final $15 \mathrm{~min}$. As graupel and snow intensify, graupel-snow collisions encounter weaker LWCs (Figs. 15a,b), favoring positive charging of graupel that falls out and hence, - CGs.

\section{b. Charge budget of STEPS simulation}

Figure 16 shows, of all charge separated (about $200 \mathrm{kC}$ ), cloud-ice-graupel, snow-graupel, and snow-cloud-ice collisions contribute $90 \%, 9.5 \%$, and $0.5 \%$, respectively. Similarly, $70 \%$ of charge-separating collisions are for graupel on cloud ice (or "crystals"), $12 \%$ for graupel on snow and $18 \%$ for snow on cloud ice. Efficacy of charging in any collision involving snow is reduced by its low bulk density (via $\Xi$ ), despite having a wide area of contact. Throughout the simulation $80 \mathrm{kC}$ of each polarity is neutralized by ICs (10 C per IC). For all -CGs only $1.7 \mathrm{kC}$ of ambient positive charge is neutralized while $-2.5 \mathrm{kC}$ is sent to ground. In the simulation a net positive charge of $4.7 \mathrm{kC}$ is lost from precipitation falling to ground, creating a net negative charge of the storm. When the storm decays, most of the charge returns to air as ions/charged aerosols when condensate evaporates. Of the $200 \mathrm{kC}$ separated in total, $98 \%$ is separated in convective ascent with only $2 \%$ in layer cloud.

Passive tagging tracers were added to AC to track components of amounts of crystals and snow originating from each of three types of secondary ice production (SIP) (section 2a), heterogeneous and homogeneous ice nucleation. They show rebounding collisions involving homogeneous, heterogeneous, and secondary ice account for $1 \%, 5 \%$, and $94 \%$ of charge separated, respectively (Fig. 16). Rebounding collisions of cloud-ice crystals with graupel prevail in charge separated by secondary ice. The sequence of events in the AC simulation is

1) graupel forms by riming of snow;

2) secondary ice fragments (cloud-ice crystals) are emitted by snow-graupel collisions;

3) fragments collide with graupel to separate charge and grow to form (charged) snow.

This is a feedback, with event 3 causing event 1 again. Overall, graupel charges positively for most $(70 \%)$ of all charge separated in its collisions. This fraction increases with time. Budgets of numbers of ice particles from each process (e.g., SIP) are in Part II of this work (also Phillips et al. 2017b). Regarding event 


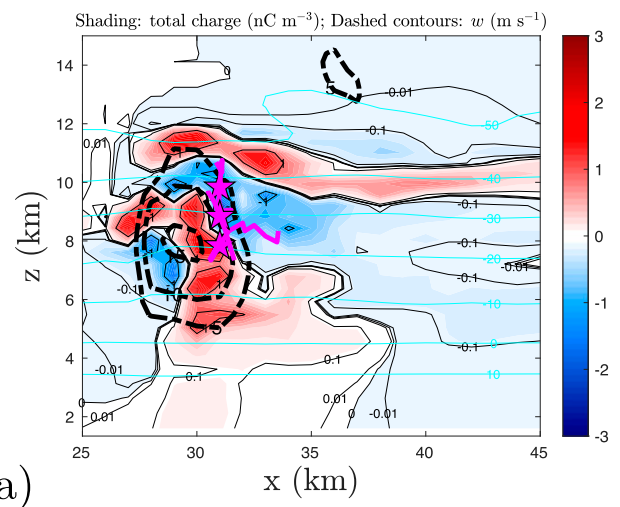

(a)
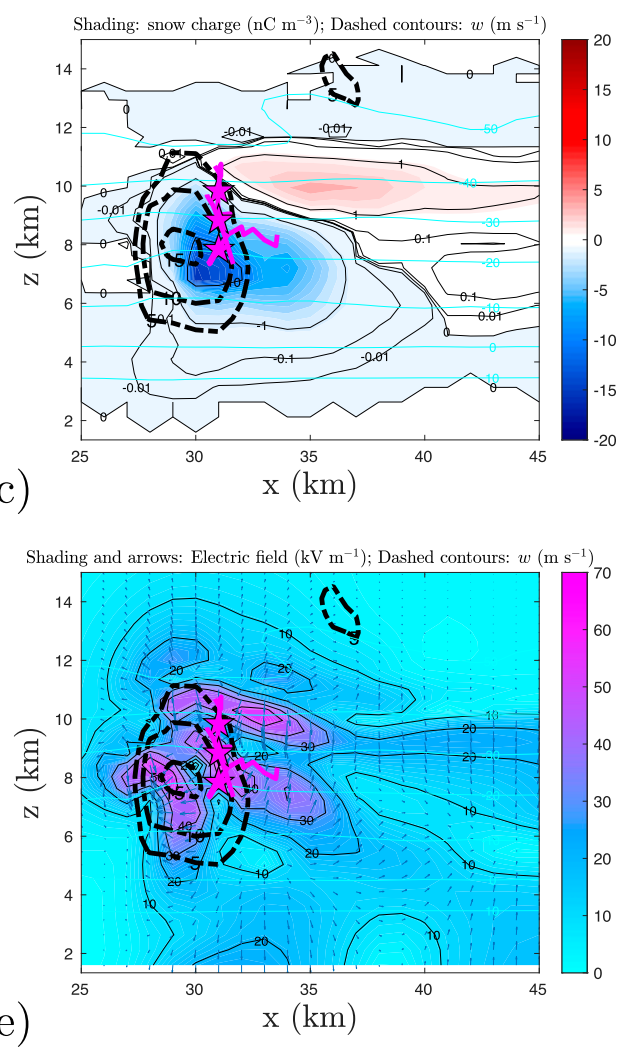

(b)
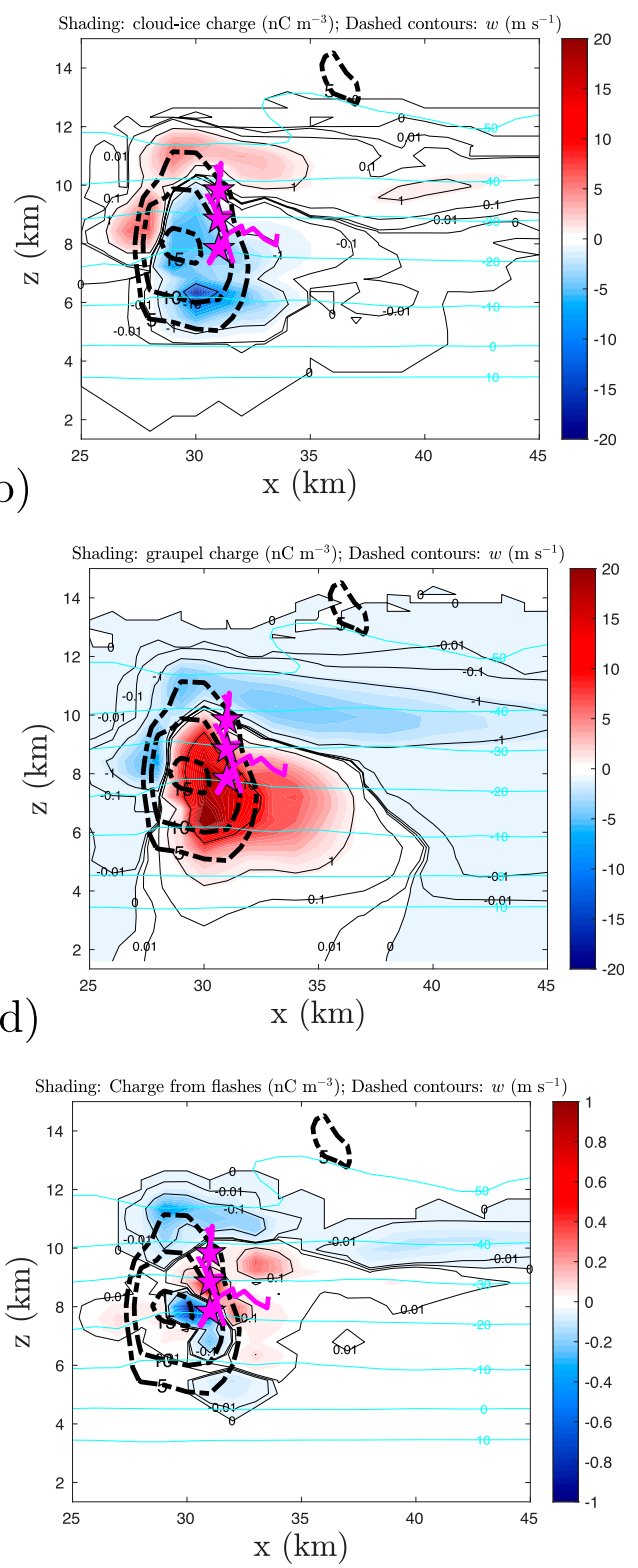

FIG. 12. Snapshots at 0055 UTC from the control run by AC of the STEPS case showing: densities of charge ( $\mathrm{nC} \mathrm{m}^{-3}$, shading) in (a) total, and on (b) cloud-ice particles, (c) snow, and (d) graupel; (e) electric field strength $\left(\mathrm{kV} \mathrm{m}^{-1}\right.$, shading) and electric field vectors (arrows); and (f) charge acquired by cloud from flashes after neutralization ( $\mathrm{nC} \mathrm{m}^{-3}$, shading). For each quantity, a vertical slice at $y=29 \mathrm{~km}$ through the trigger points of three flashes triggered near 8 and $11 \mathrm{~km}$ MSL is shown. On all snapshots are marked the bidirectional leaders (magenta lines) traced from the trigger points (magenta filled stars) for the flashes at 0055 UTC. Vertical velocity $(w)$ of convective ascent (thick black dashed contours, spaced by $5 \mathrm{~m} \mathrm{~s}^{-1}$ ) and isotherms (thin cyan contours, spaced by $10 \mathrm{~K})$ are superimposed on each.

2, AC includes a representation by Phillips et al. (2017a) of fragmentation of snow crystals in collisions with graupel based on observations by Vardiman (1978).

In convective cores, charging favors moderate conditions away from the fastest and coldest mixed-phase ascent aloft, which explains the predominant positive charging of graupel (Fig. 17a). Figure 18 shows most of this charging of graupel occurs at $-20^{\circ}<T<-10^{\circ} \mathrm{C}$ and moderate convective ascent $<15 \mathrm{~m} \mathrm{~s}^{-1}$ when LWC is weak (e.g., $<0.5 \mathrm{~g} \mathrm{~m}^{-3}$ ), where graupel is abundant. Negative charging prevails in extreme ascent $\left(>20 \mathrm{~m} \mathrm{~s}^{-1}\right)$ at $T<-20^{\circ} \mathrm{C}$ aloft.

Figure 17 a confirms that positive charging of graupel/hail is due to scarcity of cloud liquid and mostly occurs at LWCs below the weaker LWC charge-reversal line (between regions 


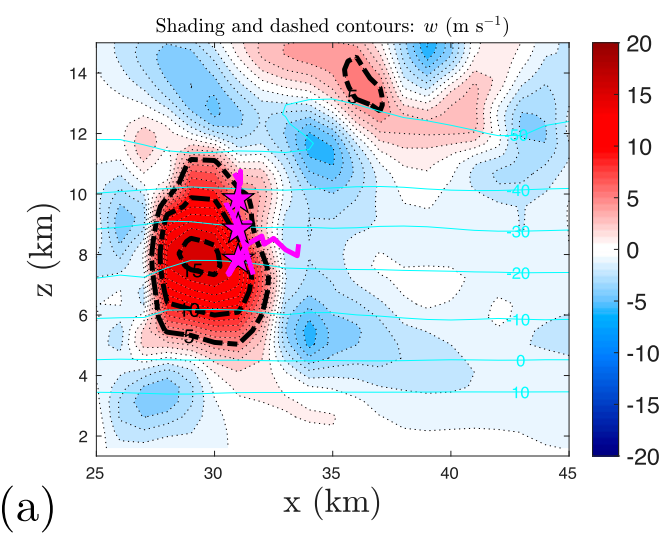

(b)
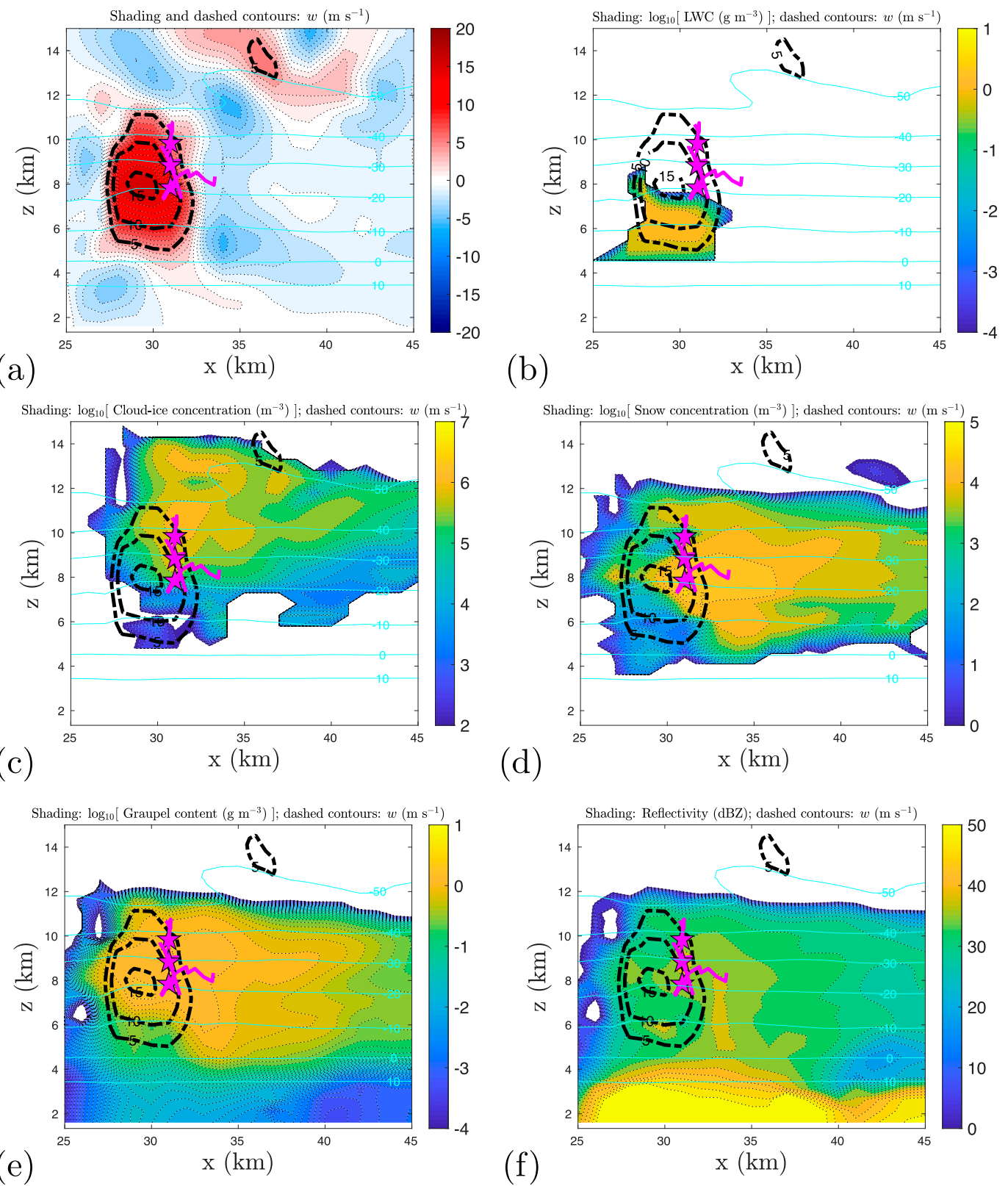

FIG. 13. Snapshots at 0055 UTC, plotted as in Fig. 12, for a vertical slice at a similar position $(y=28 \mathrm{~km})$ through the center of the updraft core for the same three flashes, of (a) vertical velocity ( $\mathrm{m} \mathrm{s}^{-1}$, shading), (b) cloud-liquid content $\left(\log _{10}\left[\mathrm{~g} \mathrm{~m}^{-3}\right]\right.$, shading), both number concentrations $\left(\log _{10}\left[\mathrm{~m}^{-3}\right]\right.$, shading) of (c) cloud ice and (d) snow; (e) the mass content $\left(\log _{10}\left[\mathrm{~g} \mathrm{~m}^{-3}\right]\right.$, shading) of graupel; and (f) radar reflectivity ( $\mathrm{dB} Z$, shading). Vertical velocity (w) of convective ascent (thick black dashed contours, spaced by $5 \mathrm{~m} \mathrm{~s}^{-1}$ ) and isotherms (thin cyan contours, spaced by $10 \mathrm{~K}$ ) are superimposed on each. The trigger and leaders of the same three flashes from Fig. 12 are shown similarly (magenta). Black numbers labeling the black dashed contours refer only to vertical velocity. There are no number labels on contours of shaded quantities.

2 and 4). There, group 2 schemes (Saunders et al. 1991; Saunders and Peck 1998) would yield a polarity of charging (negative for graupel; section 2) opposite to that in AC. The stronger LWC charge-reversal line (between regions 3 and 4 ) is precluded by the adiabatic LWC, so is almost never reached by AC here. Generally, the choice of charging scheme is critical for polarity of charging (e.g., Jayaratne and Saunders 1984). Williams et al. (1991) identify region 3 with wet growth in the laboratory study, which in reality is attainable by large enough hail.

Figure 17b shows average LWC increasing with both ascent and subzero temperature. Most charging occurs in convective ascent where average LWCs are $0.1-1 \mathrm{~g} \mathrm{~m}^{-3}$. However, charging rates 


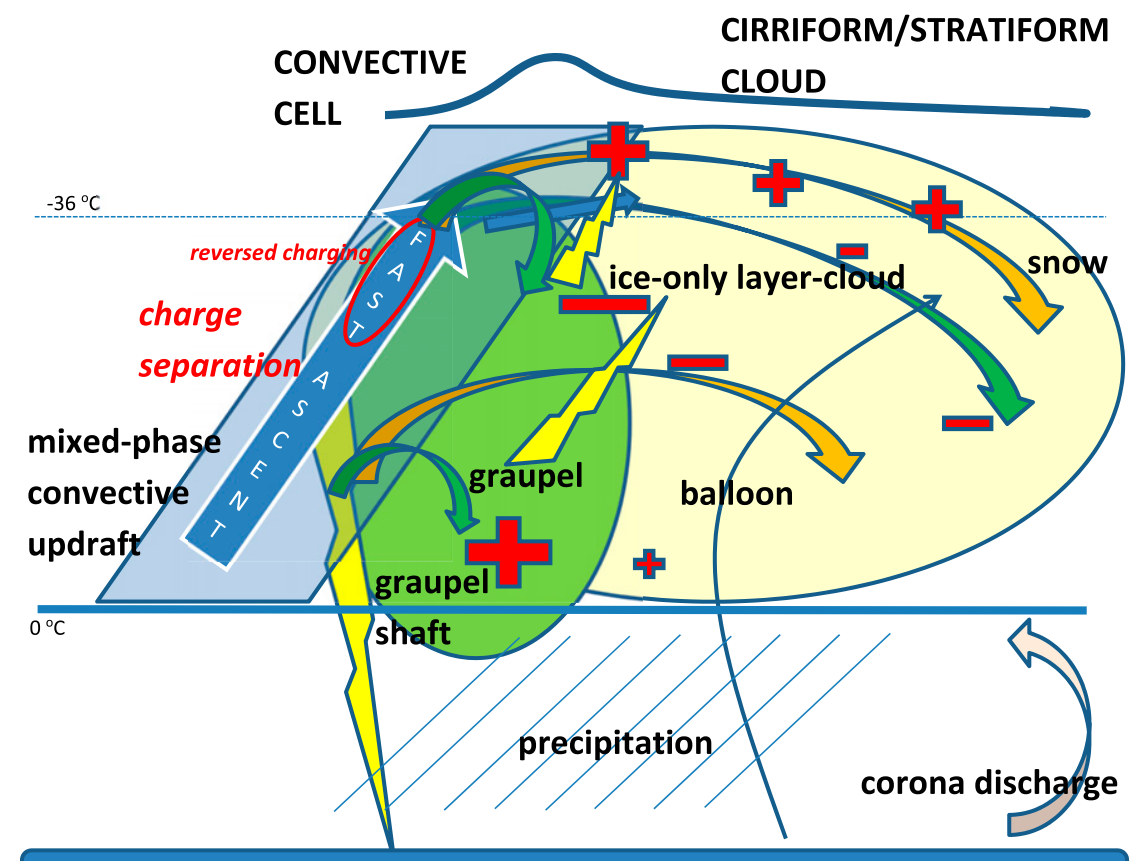

GROUND

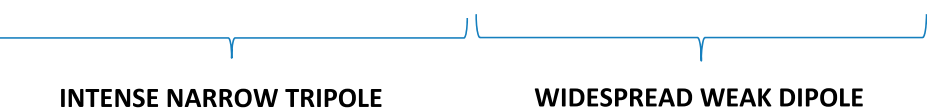

FIG. 14. Schematic diagram of charge distributions in the convective updrafts and their stratiform/cirriform outflow. Charged graupel is depicted by dark green shorter curved arrows while charged snow and cloud ice is with orange longer curved arrows. Graupel governs the net charge in the intense tripole of the charged graupel shaft (green narrower ellipse) and the net charge of the weak dipole in the layer cloud (light beige wider ellipse) is dominated by snow. Lightning (light yellow jagged symbol) occurs in the vicinity of this intense graupel shaft near the cell. Graupel is charged with opposite polarities between the warm and cold levels in the convective updraft (see two points of intersection of dark green and orange curved arrows) due to the temperature dependency of charge separation. Charging in the reverse sense (negative for graupel) is denoted by a red ellipse. Fallout of the positive graupel (lower positive symbol) leaves net negative charge from the cloud ice/snow at midlevels in the vicinity of the convective core. The balloon ascent is also depicted (thin black line).

must strongly increase with graupel amount, and graupel depletes supercooled liquid by riming. Transient depressions of LWC (arrow in Fig. 17a) from episodes of copious graupel make the overall charging positive for graupel (the polarity for mean LWC in Fig. $17 \mathrm{~b}$ at $-15^{\circ} \mathrm{C}$ is belied by Fig. 18). Although the mean LWC of updrafts $>5 \mathrm{~ms}^{-1}$ (dotted line in Fig. 17a) is mostly in region 4 (negative), most charging occurs in region 2 (positive). Mean LWC would need to be far higher for negative charging to prevail overall.

In summary, charging in graupel-crystal collisions, involving fragments of ice emitted mostly in prior graupel-snow collisions, determines the simulated electrification.

\section{Discussion}

There are some limited biases in the simulation, despite AC predicting electrical quantities consistent with the observations. A predicted peak in the profile of triggering altitudes is too high by $2 \mathrm{~km}$ and too narrow, while the lower positive charge center in the large-scale tripole may be too weak. Negative LMA sources seem too high by about $1 \mathrm{~km}$. Possible reasons for these biases are as follows. Charging was measured by Takahashi (1978) at only one pair of sizes and one impact speed for the rimer and crystals, and not for snow. Assumptions on how to extrapolate charging to other conditions are uncertain. Avila and Pereyra (2000) observed a dependency of charging on droplet size missed by schemes; droplet size governs density and roughness of rimers. Inductive charging (M05) is omitted by AC. Uncertain parameters for flashes include $\chi, L_{\chi}$,

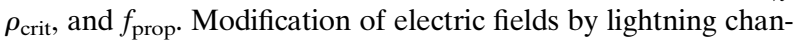
nels is neglected by AC, and influences their propagation and neutralization of charge (Williams et al. 1985). Nevertheless, reasonable results with AC were obtained here anyway.

The Takahashi charging scheme was used as it yielded superior prediction of observations here (Part II compares schemes of groups 1 and 2). -CGs were missing without it. Comprehensive validation for many quantities (section 4; 


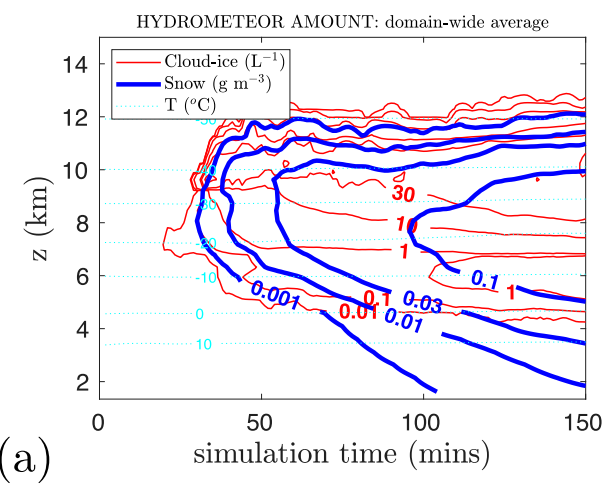

CHARGE DENSITY OF CLOUD-ICE $\left(\mathrm{nC} \mathrm{m}^{-3}\right)$ : domain-wide average

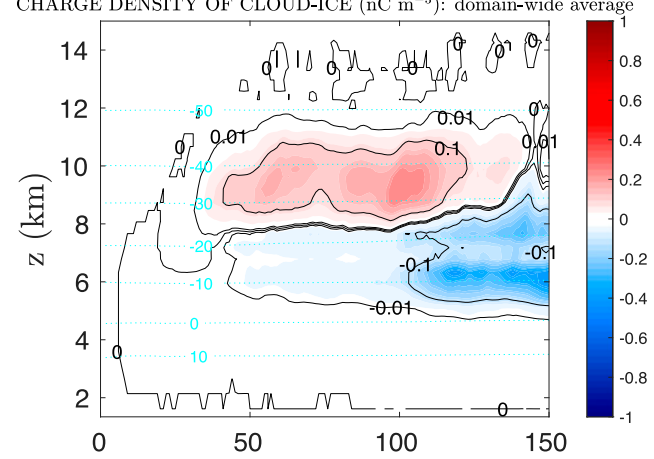

(c) simulation time (mins)

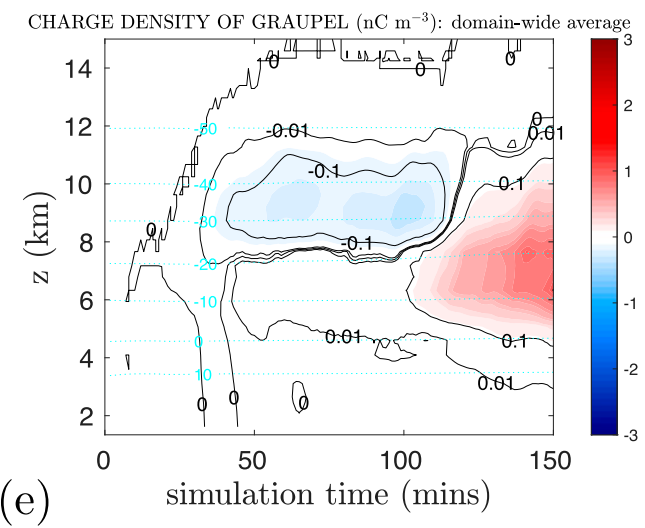

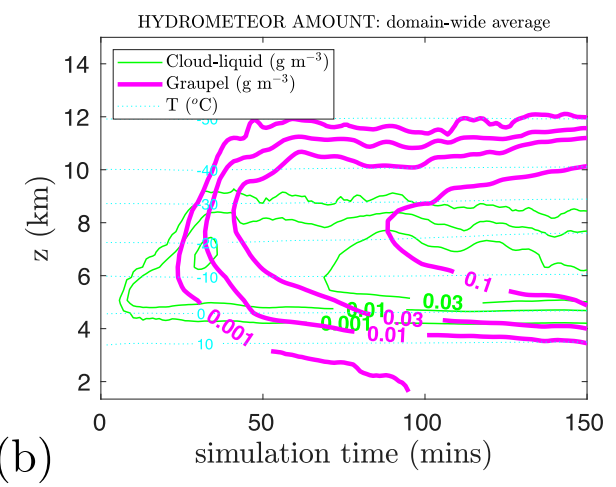
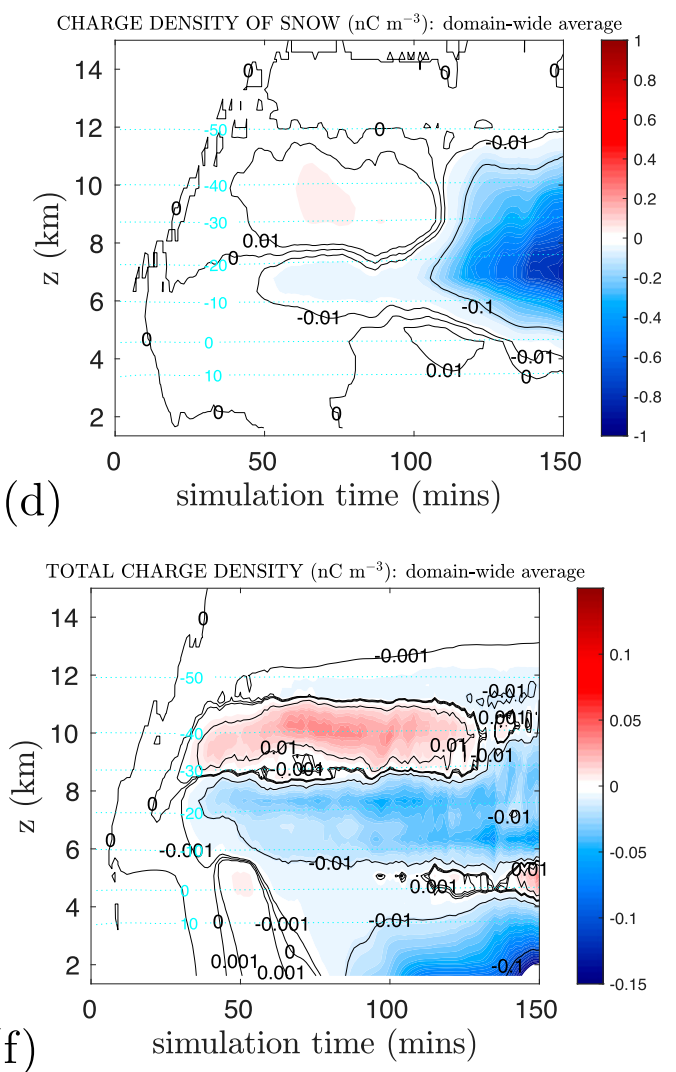

(f)

FIG. 15. Evolution through the simulation of domain-wide unconditional averages of microphysical properties and charge densities. In (a) and (b) are snow, cloud-liquid, and graupel/hail contents $\left(\mathrm{g} \mathrm{m}^{-3}\right)$ as well cloud-ice crystal number concentrations $\left(\mathrm{L}^{-1}\right)$. Space charge densities $\left(\mathrm{nC} \mathrm{m}^{-3}\right)$ are shown for (c) cloud ice, (d) snow, (e) graupel/hail, and (f) total charge. Isotherms (cyan dotted contours, spaced by $10 \mathrm{~K}$ ) are superimposed on each.

Phillips et al. 2017b), and advanced schemes of ice initiation, together preclude any balances of compensating errors from schemes causing a semblance of accuracy for the wrong reasons, as can often occur (e.g., Murphy et al. 2007; Hourdin et al. 2017). Yet it is unclear if the Takahashi scheme is accurate for all storms generally.

Since it falls much faster than snow to ground, graupel has a space charge predicted to be of opposite polarity to the net charge in the central region of the large-scale tripole (section 5a). Bateman et al. (1999) observed in a thunderstorm that graupel often had opposite polarity to the net charge, which at midlevels was not dominated by precipitation (see Bruning et al. 2010). Moreover, corona discharge at the ground in nature creates an upward stream of ions with opposite current to that of precipitation ("mirror image effect"; e.g., Simpson 1949). Soula et al. (2003) observed that charge on surface precipitation is from loss of charge by the cloud and not from any "Wilson (1929) capture" of ions. The mirror image effect in nature is due to charged precipitation (normally positive) to ground causing an opposite net (normally negative) charge on the storm cloud, causing corona discharge and CGs as responses. 


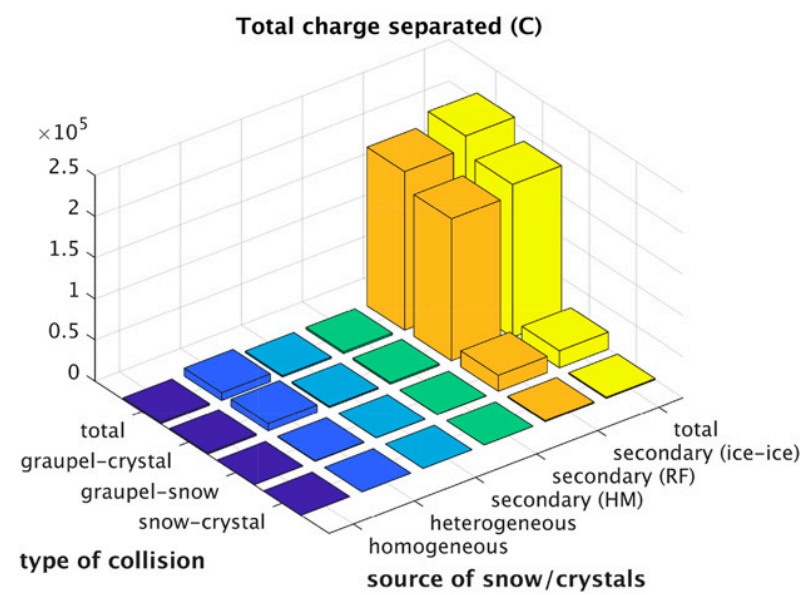

FIG. 16. Budget of total charge separated by collisions of various types of ice tracked with tagging tracers for the entire 3D simulation. Components are shown for graupel-crystal, snow-crystal, and graupel-snow collisions (type of collision), subdivided according to the prior nucleation source of the crystals (i.e., cloud ice) or snow. Total amounts are $0.002,0.01$, and $0.19 \mathrm{MC}$ for homogeneous (dark blue), heterogeneous (blue) and secondary (cyan: HM process; green: raindrop-freezing fragmentation; orange: breakup in ice-ice collisions) ice initiation, and 0.18, 0.02 and $0.001 \mathrm{M} \mathrm{C}$ for graupel-crystal, graupelsnow, and snow-crystal collisions (yellow: totals for all sources), respectively. In this storm, the secondary ice production is almost all (99.995\%) due to fragmentation in ice-ice collisions, with only minor contributions from raindrop-freezing breakup and the HM process (about $0.005 \%$ ). Homogeneous freezing is predominantly $(99.8 \%$ ) that of supercooled cloud droplets in convective ascent near $-36^{\circ} \mathrm{C}$.

In an inverted STEPS storm simulated by Kuhlman (2004), graupel was predicted to charge positively in extreme ascent rich in LWC, but negatively elsewhere; in weaker ascent, charge on crystals/snow (positive) governed central net charge (positive). It is consistent with our simulated normal storm but with polarity reversed (section $5 \mathrm{~b}$ ). For both storms, largescale charge structure is due to the widespread weaker convective ascent having a net charge opposite to that on graupel falling out. In our normal storm, graupel charges positively at LWCs (Fig. 17a, region 2) below the weaker-LWC charge reversal line $\left(1\right.$ to $0.3 \mathrm{~g} \mathrm{~m}^{-3}$ at $-10^{\circ}$ to $\left.-20^{\circ} \mathrm{C}\right)$.

Why was our storm normal in charge structure? The reason is that graupel/hail was mostly charged positively, falling out and leaving a negative charge center of the tripole with -CGs. This positive charging was due to updrafts not strong enough for the storm to be inverted, despite cloud base being high enough (Williams et al. 2005; Carey and Buffalo 2007). CAPE in the present STEPS case was mild (about $700 \mathrm{~J} \mathrm{~kg}^{-1}$ ). If ascent had been faster and CAPE higher, this would have promoted LWC (Fig. 17b) and ice precipitation, with negative charging of graupel/hail (Fig. 17a), inverted structure and +CGs (Eddy 2018). To be inverted, cloud base must not be so warm that "warm rain" depletes cloud liquid too early yet not so cold that adiabatic LWC is too weak.

In the wider context, 2000 A flows in the global DC circuit (Wilson 1921; Rycroft et al. 2000; Mach et al. 2011) including the upper atmosphere at about $250 \mathrm{kV}$ (Markson 2007).
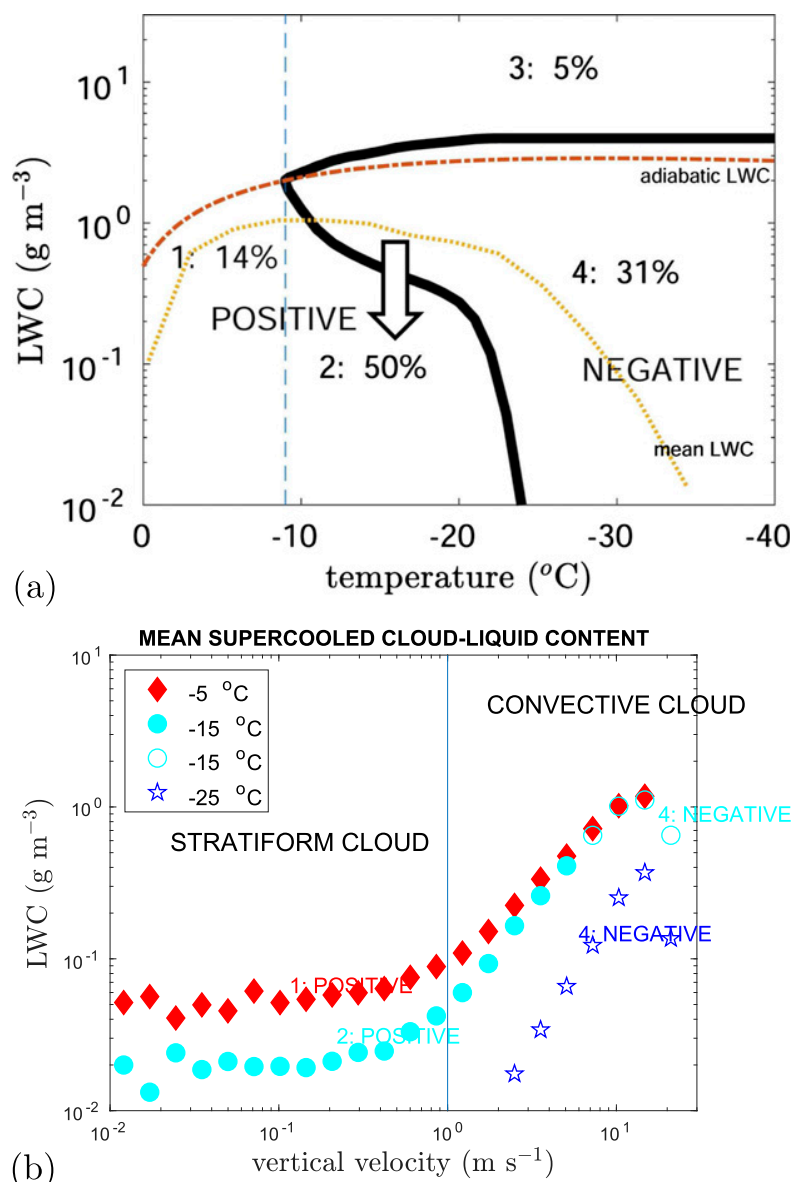

FIG. 17. (a) Percentage of all charge separated in all ice-ice collisions for each of four regions of the charge-separation phase space of supercooled liquid-water content and temperature throughout the STEPS simulation. Positive and negative regimes are separated by the thick black line (see Takahashi 1978). Regions 1,2 (blue thin dashed line), and 3 are in the regime of positive charging of the rimer (usually graupel/hail). Region 4 is in the regime of negative charging. Region 1 is for temperatures warmer than $-9^{\circ} \mathrm{C}$ and all liquid contents, while regions 2 and 3 are at colder temperatures with LWCs below and above the two charge-reversal lines, respectively. Superimposed on the plot is the adiabatic LWC for the initial sounding of the STEPS case (red thin dot-dashed line) and the mean LWC averaged over ascent $>5 \mathrm{~m} \mathrm{~s}^{-1}$ (yellow thin dotted line). The cloud base (not shown) is at about $1^{\circ} \mathrm{C}$. An open arrow denotes the effects from negative fluctuations of LWC below average, causing predominant positive charging in region 2. (b) The distribution of LWC averaged conditionally over all cloudy regions (both mixed phase and ice only) as a function of vertical velocity, $w$, for layers centered at $-5^{\circ} \mathrm{C}$ (red), $-15^{\circ} \mathrm{C}$ (cyan), and $-25^{\circ} \mathrm{C}$ (blue) in the simulation. Regions of charging from (a) corresponding to these average LWCs are labeled in (b). Closed and open symbols denote positive and negative charging of graupel, respectively, in (b). Convective and stratiform clouds are separated by $w=1 \mathrm{~m} \mathrm{~s}^{-1}$ (thin full line).

Thunderstorms and electrified shower clouds (ESCs) act as a "battery" driving current up to the upper atmosphere and a fairweather current down globally (Williams and Mareev 2014). Each land lightning storm gives $1 \mathrm{~A}$ on average (0.1-8 A 


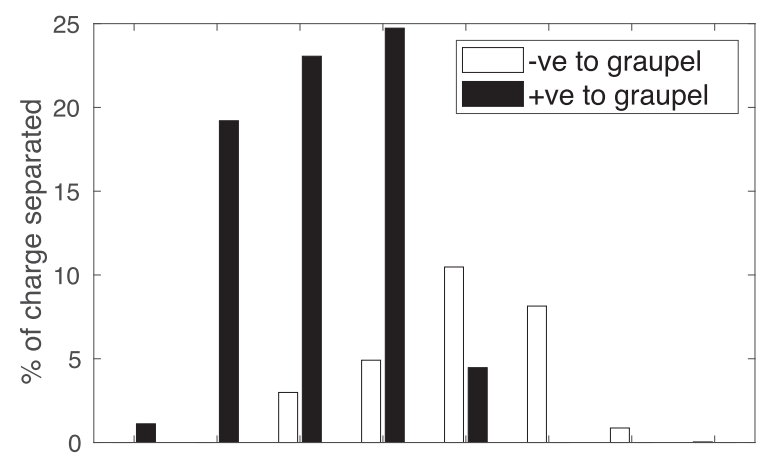

(a)

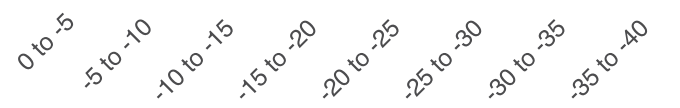

temperature $\left({ }^{\circ} \mathrm{C}\right)$

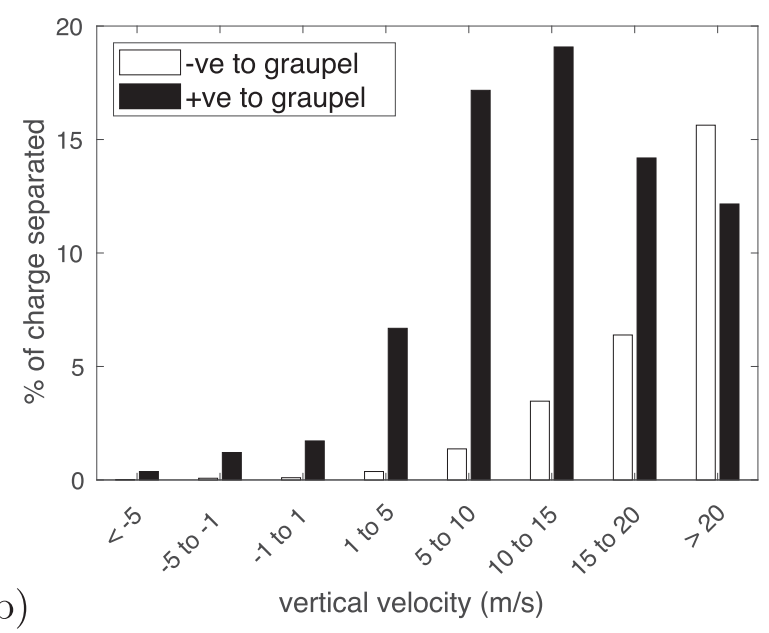

FIG. 18. Percentages of all charge separated involving graupel in ranges of (a) temperature and (b) vertical velocity are shown. Black and white denote positive and negative charging of graupel/ hail, respectively. This is for the same overall budget from the STEPS simulation given in Fig. 16.

individually) to this "Wilson current" (Mach et al. 2010). Yet ESCs may dominate it globally (Liu et al. 2010).

Is our STEPS simulation consistent with the global circuit? In the $\mathrm{AC}$ charge budget (section $5 \mathrm{~b})-2.5 \mathrm{kC}$ goes to ground in flashes and $+4.7 \mathrm{kC}$ in precipitation, with the former smaller in absolute magnitude than the latter as it is a response to the latter. Their ratio $(-0.53)$ is consistent with Wormell's (1953) observations $(-20: 30)$. Corona discharge at the ground creates current flowing up toward the lower negative charge of the weak widespread dipole (beige arrow, Fig. 14), and would greatly augment the CG current in reality. Corona discharge was not simulated in the present paper. An order-of-magnitude estimate yields a current up from the simulated storm of 1-2 A (appendix D), similar to observations of the Wilson current for multicell storms.

\section{Conclusions}

An electrical component was created for AC, which has emulated bin microphysics and represents many aspects of ice-ice collisions. A fractal branching law for lightning was constrained by video imagery. A charging scheme for Takahashi's laboratory observations was modified to account for area of contact with the rimer and negativity of the unobserved region. Phillips et al. (2017b) demonstrated realism of many microphysical quantities of AC for a normal storm. Here, salient observed electrical quantities, such as electric fields and occurrence of -CGs and ICs, are shown to be predicted realistically for the same simulation.

The normal tripole structure of charge in the storm is explicable in terms of Takahashi's laboratory observations with charge reversal at low temperatures. Near convection there is

1) a weak positive charge center near the freezing level from graupel charging positively, especially in weak/moderate convective ascent (regions 1 and 2, Fig. 17a);

2) a stronger negative charge center at the center of the mixedphase region from negatively charged cloud ice/snow as positively charged graupel (region 2) falls out; and

3) an upper-level positive charge center from cloud ice/snow, due to negative charging of graupel at LWCs $\left(0.1-4 \mathrm{~g} \mathrm{~m}^{-3}\right.$ for $-30^{\circ} \mathrm{C}$ ) in rapid cold ascent (region 4 ).

Transient maxima of charge in graupel/hail shafts on the side of convective updrafts govern the triggering of lightning, as shown by the case study. Most ICs connect adjacent oppositely charged regions with net charge dominated by graupel and snow/cloud ice, respectively.

Consistent with number 2 above, LMA observations of a narrow graupel/hail shaft in our normal STEPS storm (Tessendorf et al. 2007) reveal that its net charge is positive (section 5a). Conversely, in a winter storm (possibly with $+\mathrm{CGs}$ ) over the Sea of Japan, graupel was observed to be positively charged only at high subzero temperatures $\left(>-11^{\circ} \mathrm{C}\right)$ and low $\operatorname{LWC}\left(<0.4 \mathrm{~g} \mathrm{~m}^{-3}\right)$ at lower cloudy levels, and negatively charged elsewhere at most cloudy levels (Takahashi et al. 2017, section 2b) (see Kitagawa and Michimoto 1994, their Fig. 13). This, and recent laboratory observations by Pereyra et al. (2000), Berdeklis and List (2001) and Takahashi and Miyawaki (2002), seem more consistent with Takahashi's scheme than alternative schemes.

Essentially, the normal tripole of the simulated storm is from most graupel charging positively $(70 \%$ of all its charge in the storm) and falling out to leave net negative charge on snow/crystals aloft. This charging is positive as it is mostly at levels warmer than $-20^{\circ} \mathrm{C}$ and where cloud liquid is scarce (region 2 of Fig. 17a). The lower LWC charge-reversal line is crucial. Conversely, if an inverted storm were simulated by $\mathrm{AC}$, then graupel/hail would mostly be charged negatively. Yet traditionally, prevalent negative charging of graupel was hitherto assumed for storms with a normal tripole charge structure (section 5a; e.g., PK97).

Supercooled liquid is scarce during charging for several reasons. High concentrations of secondary ice deplete liquid, with average LWC of only $1 \mathrm{~g} \mathrm{~m}^{-3}$ aloft (Phillips et al. 2017b, their Fig. 5). Coldness of cloud base reduces adiabatic LWC (Clausius-Clapeyron relation), although warm-based storms too can have low LWC; theirs is depleted by coalescence. Actual LWC aloft can be further impacted by factors (cloud width, shear) affecting entrainment mixing. Moreover, episodes of intense charging coincide with transient shafts of copious large graupel depleting LWC by riming. Negative fluctuations of LWC 
below average govern charging, explaining the prevalent positive charging of graupel (arrow in Fig. 17a). Charging increases strongly with abundance of large graupel, due to SIP and higher cross-sectional areas for collisions.

"Tagging tracers" in AC show most charge separated is from rebounding collisions of graupel with cloud-ice crystals that originate as fragments emitted in prior graupel-snow (large crystals or aggregates) collisions. This extends our earlier finding that most ice particles initiated in the mixed phase region of this storm are from breakup in graupel-snow collisions (Phillips et al. 2017a,b) (section 1), with a scheme based on observations by Vardiman (1978). Such an electrical role of breakup may be obscured in a sensitivity test by compensating responses among various processes (Part II). This role for graupel in charging is consistent with the concept of the "graupel dipole" in electrification of anomalous (+CGs from fallout of negatively charged graupel) cold-based winter storms (Williams 2018), except with polarities reversed. Also, ice from homogeneous freezing does not participate in the charging of the simulated electrification, despite yielding many crystals.

$\mathrm{AC}$ is the only model of storm electrification to represent both breakup in ice-ice collisions comprehensively and its impact on electrification. In the literature, few other studies have shown simulations of lightning for cold-based storms. They generally do not show validated predictions of microphysical quantities such as ice number concentration or LWC.

In AC simulations (see also Part II), -CGs (+CGs) are a response to positively (negatively) charged surface precipitation from similarly charged graupel falling out, as this removal of charge creates the total net charge of the storm aloft. Hypothetically, if there were somehow no charged precipitation falling toward ground, the total net charge in the storm would be almost zero, even if it had some charge structure. There would presumably be no - CGs, as electric fields below cloud base would be too weak. The electric field around a dipole of two point charges with zero total charge falls off sharply, being inversely proportional to the cube of distance from it, instead of the square of distance for a point charge (Grant and Phillips 1988).

In summary, high concentrations of ice crystals, predicted from breakup in ice-ice collisions and observed by aircraft, reduce LWC in convection by the Wegener-Bergeron-Findeisen effect and by riming (Part II). The convective cloud is mostly in Takahashi's low LWC regime. A normal tripole with central net negative charge arises from positive charging of graupel that falls out, causing positively charged precipitation to ground, a negative total net charge of the simulated storm aloft and hence -CGs in response.

Acknowledgments. This work was completed for a past award (2009-12) from the National Science Foundation (NSF) to the first author (VTJP). It was supported also by current awards to VTJP from the Swedish Research Council ("VR"; 2015-05104), regarding aerosol effects on cold clouds, and U.S. Department of Energy (DE-SC0018932, DE-SC0018967) about ice initiation in clouds, in addition to a recent award from the Crafoord Foundation (20180783). We acknowledge advice from Burgesser, Dwyer, Dye, Jayaratne, Krehbiehl, MacGorman, Mansell, Marshall, Saunders, Takahashi, Tinsley, Wettlaufer, Wiens, Williams, and Yair.

\section{APPENDIX A}

\section{List of Symbols}

Table A1 provides a list of symbols, their meanings, and values and units.

\section{APPENDIX B}

\section{Description of $\mathbf{A C}$}

Development of AC as a model coupling the representations of cloud microphysics and aerosol chemistry began with inclusion by Phillips et al. (2009) of several aerosol species in their cloud model. Total mass and number of hydrometeors in each microphysical species are advected and diffused as bulk prognostic variables in AC ("two-moment" approach). Microphysical processes are treated by discretizing the size distributions with temporary grids of bins ("emulated bin microphysics"). These schemes were created in the framework of the Weather Research and Forecasting (WRF) Model and validated against coincident observations for cases of deep convection (Phillips et al. 2007, 2008, 2009, 2013, 2015; Kudzotsa 2014; Kudzotsa et al. 2016). The two-moment approach was extended to precipitation by Phillips et al. (2017b). Other schemes are from WRF (Skamarock et al. 2005), for dynamics, subgrid-scale mixing, the planetary boundary layer, and surface layer.

Mass mixing ratios for rime on snow and cloud ice, and for liquid on graupel/hail, are predicted. A scheme for wet growth of graupel/hail is included (Phillips et al. 2014). The known mechanisms of initiation of cloud droplets and ice particles are treated in terms of dependencies on chemistry, size, and loading of aerosols. Homogeneous freezing of each soluble aerosol species is predicted.

Preferential evaporation of smaller cloud droplets during homogeneous freezing of cloud liquid near $-36^{\circ} \mathrm{C}$ is represented (Phillips et al. 2007). The larger droplets freeze sooner during ascent through the homogeneous freezing layer (about $-36^{\circ}$ to $-37^{\circ} \mathrm{C}$ ) with an observed size dependence (reviewed by PK97). Their vapor growth when frozen may cause subsaturation depending on the ascent. If so, then the remaining supercooled droplets may evaporate instead of freezing. Smaller sizes are preferred for evaporation because the smaller droplets freeze later.

The prognostic aerosol scheme predicts in-cloud aerosol size distributions (ASDs) of seven chemical species of aerosols (Phillips et al. 2009): mineral dust, black carbon, soluble organics, and primary biological aerosol particles (PBAPs), sulfate, nonbiological insoluble organics, sea salt. No chemical reactions are represented for these species, however. ASDs of components of each aerosol species that are (i) interstitial, and immersed in (ii) cloud particles and (iii) precipitation, are predicted by the model. Two-moment bulk variables for number and mass define each sulfate mode (Kudzotsa et al. 2016). Two modes of operation are possible: either aerosol species in the cloud-free environment are prescribed (no feedback) or these are predicted with bulk prognostic variables nudged toward observations (feedback from cloud to environment). In the present paper, the latter mode was used. 
TABLE A1. List of symbols.

\begin{tabular}{|c|c|c|}
\hline Symbol & Meaning & Value and units \\
\hline$D$ & Particle diameter or maximum dimension & $\mathrm{m}$ \\
\hline$D_{i}$ & Maximum dimension of snow crystal & $\mathrm{m}$ \\
\hline$D_{i, *}$ & Thresholded dimension of snow crystal & $\mathrm{m}$ \\
\hline$D_{0}$ & Value of $D_{i}$ in Takahashi's laboratory experiment & $10^{-4} \mathrm{~m}$ \\
\hline $\mathbf{E}$ & Electric field vector $(\mathbf{E}=-\nabla \phi)$ & $\mathrm{V} \mathrm{m}^{-1}$ \\
\hline$E$ & Electric field strength $(E=|\mathbf{E}|)$ & $\mathrm{Vm}^{-1}$ \\
\hline$E_{z}$ & Vertical component of $\mathbf{E}$ & $\mathrm{Vm}^{-1}$ \\
\hline$E_{\text {init }}$ & Critical electric field for dielectric breakdown & $\mathrm{Vm}^{-1}$ \\
\hline$f_{\text {Taka }}$ & Interpolating function of $T$ & - \\
\hline$f_{\text {prop }}$ & Fraction of preflash electric field for propagation & 0.05 \\
\hline$g$ & Ratio of excess corona discharge (beyond precipitation charge) to charge from CGs & - \\
\hline$j$ & Number of spherical ice-shell thicknesses between a point and the trigger point of a flash & Positive integer \\
\hline LWC & Liquid water content of cloud droplets & $\mathrm{g} \mathrm{m}^{-3}$ \\
\hline LWC* & Value of LWC used for input to $Q_{\text {Taka }}$ & $\mathrm{g} \mathrm{m}^{-3}$ \\
\hline$L_{\chi}$ & Length scale of lightning & $1400 \mathrm{~m}$ \\
\hline$\delta \overline{\bar{L}}$ & Longest diagonal width of grid box & $\mathrm{m}$ \\
\hline $\operatorname{MIN}(a, b)$ & Function returning the minimum value of either $a$ or $b$ & $a$ or $b$ \\
\hline$N$ & $\begin{array}{l}\text { Number of junction points of branches ( }>0.5 \mathrm{~km} \text { in length) inside sphere of radius } r \text { centered on trigger } \\
\text { point of flash }\end{array}$ & - \\
\hline$N_{\text {grid }}$ & Number of grid points occupied by branches ( $>0.5 \mathrm{~km}$ in length) in $j$ th hemispherical shell & - \\
\hline$\delta N_{\cap}$ & Number of junction points of branches ( $>0.5 \mathrm{~km}$ in length) inside hemispherical shell $(\delta r)$ & - \\
\hline$q$ & Charge per particle & $\mathrm{C}$ \\
\hline$Q_{\text {Taka }}$ & $\begin{array}{l}\text { Charge transferred to the rimer per collision of snow/crystal particles }(100 \mu \mathrm{m}) \text { in Takahashi's laboratory } \\
\text { experiment }\end{array}$ & $\mathrm{C}$ \\
\hline$\delta Q$ & Charge transferred to the rimer per collision between a rimed precipitation and snow/crystal particles & $\mathrm{C}$ \\
\hline$r$ & Radius of spherical shell centered on trigger point of flash (or distance from convective core) & $\mathrm{m}$ \\
\hline$\delta r$ & Thickness of spherical shell & $\mathrm{m}$ \\
\hline$T$ & Temperature & ${ }^{\circ} \mathrm{C}$ \\
\hline$V_{i}, V_{p}$ & Fall speeds of crystal and rimed precipitation particles & $\mathrm{m} \mathrm{s}^{-1}$ \\
\hline$x$ & Label for microphysical species (e.g., graupel/hail, snow, crystals) or air & - \\
\hline$w$ & Vertical velocity of air & $\mathrm{m} \mathrm{s}^{-1}$ \\
\hline$\alpha$ & Factor for extrapolating observed charge transferred per collision to any collision & - \\
\hline$\beta$ & Constant in power law for charge per particle & $\mathrm{Cm}^{-\gamma}$ \\
\hline$\gamma$ & Exponent in power law for charge per particle & - \\
\hline$\zeta$ & Polarity of plasma in the flash & 1 or -1 \\
\hline$\kappa$ & Number of grid boxes per branch junction point & 7 \\
\hline$\Xi$ & Factor proportional to bulk density of snow, multiplying the observed charging & - \\
\hline$\xi$ & Interpolating fraction over temperature & - \\
\hline$\rho_{a}$ & Air density & $\mathrm{kg} \mathrm{m}^{-1}$ \\
\hline$\rho_{\mathrm{ch}}$ & Mixing ratio of charge in plasma channel of lightning (averaged over grid box) & $\mathrm{C} \mathrm{kg}^{-1}$ \\
\hline$\rho_{\text {crit }}$ & Critical value of space charge mixing ratio for branching & $0.2 \times 10^{-9} \mathrm{C} \mathrm{kg}^{-1}$ \\
\hline$\rho_{q}$ & Total mixing ratio of ambient space charge & $\mathrm{C} \mathrm{kg}^{-1}$ \\
\hline$\rho_{q, a}$ & Space charge mixing ratio in air & $\mathrm{C} \mathrm{kg}^{-1}$ \\
\hline$\rho_{q, x}$ & Space charge mixing ratio on $x$ th microphysical species & $\mathrm{C} \mathrm{kg}^{-1}$ \\
\hline$\delta \rho_{q, a}$ & Change in $\rho_{q, a}$ & $\mathrm{C} \mathrm{kg}^{-1}$ \\
\hline$\delta \rho_{q, x}$ & Change in $\rho_{q, x}$ & $\mathrm{C} \mathrm{kg}^{-1}$ \\
\hline$\rho_{s}$ & Bulk density of snow & $\mathrm{kg} \mathrm{m}^{-1}$ \\
\hline$\phi$ & Electrical potential & $\mathrm{V}$ \\
\hline$\phi_{0}$ & Electrical potential at trigger point & $\mathrm{V}$ \\
\hline$\chi_{x}$ & Fractional contribution to surface area from $x$ th microphysical species & - \\
\hline & Exponent in fractal law for branching & 2.5 \\
\hline$\psi(\mathrm{LWC})$ & Interpolating fraction over LWC & - \\
\hline
\end{tabular}

The empirical parameterization (EP) of heterogeneous ice nucleation predicts IN activity from four of the aerosol species: dust, soot, soluble organics, and PBAPs (Phillips et al. 2008, 2013). All known types of IN activity (deposition and condensation/immersion freezing, outside-in and inside-out contact freezing, heterogeneous raindrop freezing) are represented. Regarding secondary ice initiation, fragmentation in iceice collisions was included with a new energy-based theory by Phillips et al. (2017a). More details of AC are given by Phillips et al. (2017b). 
Regarding nonelectrical aspects, four minor changes to the cloud model were made for the present paper. They have little effect on the model validation shown by Phillips et al. (2017b), which still applies. First, a lateral sponge on the sides of the domain was included to avoid reflection of horizontally propagating gravity waves from open lateral boundaries. Second, temperature perturbations of warm and cold bubbles initiating convection were intensified by a factor of 3 , allowing convection in some perturbation simulations for Part II. The cold bubbles were released $10 \mathrm{~km}$ farther west than before. Third, the scheme for raindrop-freezing fragmentation from Phillips et al. (2018) was implemented. Fourth, the bulk density of graupel/hail, prescribed as a function of size, was altered to match that predicted explicitly with a microphysical simulation of a particle growing by riming (Phillips et al. 2001, 2002, 2005) at fixed supercooled LWC (about $1 \mathrm{~g} \mathrm{~m}^{-3}$ ) and temperature $\left(-5^{\circ}\right.$ to $\left.-30^{\circ} \mathrm{C}\right)$. The particle grew from a snow particle of $0.2 \mathrm{~mm}$ to $10 \mathrm{~cm}$ in size. The chance of wet growth and shedding of liquid was included. The bulk density of graupel/hail is now prescribed as $150 \mathrm{~kg} \mathrm{~m}^{-3}$ for graupel $<1 \mathrm{~mm}, 800 \mathrm{~kg} \mathrm{~m}^{-3}$ for hail $>5 \mathrm{~cm}$, and linearly interpolated over size in between.

\section{APPENDIX C}

\section{Formulation for Number of Grid Boxes per Branch Junction Point in Electrical Scheme}

In the electrification scheme of AC (section 2), although both leader channels from a given trigger point are traced analytically, the branching is handled statistically instead. The number of grid boxes per branch junction point, $\kappa$, governs which grid points contain branches around any leader. An expression for $\kappa$ in terms of the length scales of the grid box and branches is formulated as follows.

Consider the special case when each branch $\left(L_{\chi}\right)$ is a straight line of one diagonal grid box in length, extending out radially (when $L_{\chi}=\delta \bar{L}$ ). There are two branches per junction point on average, oriented radially from the trigger point. If a junction point is at the corner of two diagonally contacting grid boxes, then two grid boxes are entered. Any deviation of orientation of the pair of branches from the line of longest diagonals will increase the number of grid boxes entered to at least five. An idealized numerical model offline with a cubic grid $(100 \times$ $100 \times 100$ grid points) is constructed to yield a schematic depiction of a flash consisting of such branch pairs:

- many branch junction points randomly located throughout grid;

- trigger point of flash at center of cubic domain;

- two parallel branches, radially oriented relative to the trigger, inward and outward from each junction point, each branch being of length $L_{\chi}=\delta \bar{L}$;

- line traced numerically at very fine resolution along each branch, counting the number of boxes crossed by each branch.

For simplicity, the branch pairs are not connected to one another. This simple model confirms the number of grid boxes per branch is $\kappa \approx 6$ on average. With more realism, curvature of branches and both branches in a pair having different directions would increase the average number of grid boxes entered by each branch pair (by 1 or 2 ). Thus $\kappa \approx 7$.

In general for any length scale of branches, $\kappa \propto L_{\chi} / \delta \bar{L}$. Consequently, $\kappa \approx 7\left(L_{\chi} / \delta \bar{L}\right)$.

\section{APPENDIX D}

\section{Order-of-Magnitude Estimate of Contribution from Simulated Storm to the Global Wilson Current}

To estimate the contribution from the simulated storm to the Wilson current through the global DC electric circuit, we use published observations of charge budget to account for the corona discharge from the ground. Corona discharge was not simulated by AC. Wormell (1953) estimated for an area of ground the long-term gain of charge $\left(\mathrm{C} \mathrm{km}^{-2} \mathrm{yr}^{-1}\right)$ in all weather: 30 for precipitation, -20 for CG flashes and -100 for corona discharge (of which a fraction, say $g$, is from thunderstorms). His observed ratio of charge to ground in flashes to that in precipitation $(-2: 3)$ agrees with $\mathrm{AC}$ (-2.5:4.7).

Suppose the ratio for thunderstorms between the gains of charge from precipitation current and from both discharges (CG flashes and corona) is $30 /(-100 g-20)=-0.25$ to -0.5 , assuming $0.5<g<1$. Applying this ratio to our simulated storm suggests a gain of charge from corona discharge of -7 to $-16 \mathrm{kC}$ at the ground. This connotes a total transfer of about 10 to $20 \mathrm{kC}$ of positive charge (CGs, corona discharge and precipitation) toward the upper atmosphere over the storm lifetime of $10^{4} \mathrm{~s}$. Consequently, our simulated STEPS multicellular storm may have contributed about $1.5 \pm 0.5 \mathrm{~A}$ to the global circuit.

This is only an order of magnitude estimate and depends on critical assumptions about corona discharge. For any storm, the corona current may occur on larger temporal and spatial scales than the convective core of the lightning, continuing long after the decay of the storm as the space charge in the air from evaporated condensate is advected.

\section{REFERENCES}

Adams, J., 1989: MUDPACK: Multigrid portable Fortran software for the efficient solution of linear elliptic partial differential equations. Appl. Math. Comput., 34, 113-146, https://doi.org/ 10.1016/0096-3003(89)90010-6.

Avila, E. E., and R. G. Pereyra, 2000: Charge transfer during crystal-graupel collisions for two different cloud droplet size distributions. Geophys. Res. Lett., 27, 3837-3840, https://doi.org/ 10.1029/2000GL012302.

Baker, M. B., E. R. Jayaratne, J. Latham, and C. P. R. Saunders, 1987: The influence of diffusional growth rates on the charge transfer accompanying rebounding collisions between ice crystals and soft hailstones. Quart. J. Roy. Meteor. Soc., 113, 1193-1215, https://doi.org/10.1002/qj.49711347807.

Barthe, C., and J.-P. Pinty, 2007: Simulation of electrified storms with comparison of the charge structure and lightning efficiency. J. Geophys. Res., 112, D19204, https://doi.org/10.1029/ 2006JD008241.

—_ G. Molinie, and J.-P. Pinty, 2005: Description and first results of an explicit electrical scheme in a $3 \mathrm{D}$ cloud 
resolving model. Atmos. Res., 76, 95-113, https://doi.org/ 10.1016/j.atmosres.2004.11.021.

—, M. Chong, J.-P. Pinty, C. Bovalo, and J. Escobar, 2012: CELLS v1.0: Updated and parallelized version of an electrical scheme to simulate multiple electrified clouds and flashes over large domains. Geosci. Model Dev., 5, 167-184, https://doi.org/ 10.5194/gmd-5-167-2012.

Bateman, M. G., T. C. Marshall, M. Stolzenburg, and W. D. Rust, 1999: Precipitation charge and size measurements inside a New Mexico mountain thunderstorm. J. Geophys. Res., 104, 9643-9653, https://doi.org/10.1029/1998JD200118.

Battan, L. J., 1965: Some factors governing precipitation and lightning from convective clouds. J. Atmos. Sci., 22, 79-84, https://doi.org/10.1175/1520-0469(1965)022<0079: SFGPAL $>2.0 . \mathrm{CO} ; 2$.

Beard, K. K., and H. T. Ochs, 1986: Charging mechanisms in clouds and thunderstorms. The Earth's Electrical Environment, National Academic Press, 114-130.

Berdeklis, P., and R. List, 2001: The ice crystal-graupel collision charging mechanism of thunderstorm electrification. J. Atmos. Sci., 58, 2751-2770, https://doi.org/10.1175/1520-0469(2001) 058<2751:TICGCC $>2.0$. CO;2.

Blyth, A. M., and J. Latham, 1993: Development of ice and precipitation in New Mexican summertime cumulus clouds. Quart. J. Roy. Meteor. Soc., 119, 91-120, https://doi.org/10.1002/ qj. 49711950905 .

—, R. E. Benestad, P. R. Krehbiel, and J. Latham, 1997: Observations of supercooled raindrops in New Mexico summertime cumuli. J. Atmos. Sci., 54, 569-575, https://doi.org/ 10.1175/1520-0469(1997)054<0569:OOSRIN > 2.0.CO;2.

Boccippio, D. J., K. L. Cummins, H. J. Christian, and S. J. Goodman, 2001: Combined satellite- and surface-based estimation of the intracloud-cloud-to-ground lightning ratio over the continental United States. Mon. Wea. Rev., 129, 108-122, https://doi.org/10.1175/1520-0493(2001)129<0108: CSASBE $>2.0 . \mathrm{CO} ; 2$.

Bringi, V. N., K. Knupp, A. Detwiler, L. Liu, I. J. Caylor, and R. A. Black, 1997: Evolution of a Florida thunderstorm during the Convection and Precipitation/Electrification Experiment: The case of 9 August 1991. Mon. Wea. Rev., 125, 2131-2160, https://doi.org/10.1175/1520-0493(1997)125<2131: EOAFTD $>2.0 . \mathrm{CO} ; 2$.

Brooks, I. M., C. P. R. Saunders, R. P. Mitzeva, and S. L. Peck, 1997: The effect on thunderstorm charging of the rate of rime accretion by graupel. Atmos. Res., 43, 277-295, https://doi.org/ 10.1016/S0169-8095(96)00043-9.

Bruning, E. C., W. D. Rust, D. R. MacGorman, M. I. Biggerstaff, and T. J. Schuur, 2010: Formation of charge structures in a supercell. Mon. Wea. Rev., 138, 3740-3761, https://doi.org/ 10.1175/2010MWR3160.1.

Brunschon, C. W., and D. Sider, 2007: Theophrastus of Eresus: On Weather Signs. Brill, 263 pp.

Carey, L. D., and K. M. Buffalo, 2007: Environmental control of cloud-to-ground lightning polarity in severe storms. Mon. Wea. Rev., 135, 1327-1353, https://doi.org/10.1175/MWR3361.1.

Cummins, K. L., M. J. Murphy, E. A. Bardo, W. L. Hiscox, R. B. Pyle, and A. E. Pifer, 1998: A combined TOA/MDF technology upgrade of the U.S. National Lightning Detection Network. J. Geophys. Res., 103, 9035-9044, https://doi.org/ 10.1029/98JD00153.

Dahl, N. A., A. Shapiro, C. K. Potvin, A. Theisen, J. G. Gebauer, A. D. Schenkman, and M. Xue, 2019: High-resolution, rapidscan dual-Doppler retrievals of vertical velocity in a simulated supercell. J. Atmos. Oceanic Technol., 36, 1477-1500, https:// doi.org/10.1175/JTECH-D-18-0211.1.

Dwyer, J. R., and Coauthors, 2004: Measurements of X-ray emission from rocket-triggered lightning. Geophys. Res. Lett., 31, L05118, https://doi.org/10.1029/2003GL018770.

— steps in cloud-to-ground lightning. Geophys. Res. Lett., 32, L01803, https://doi.org/10.1029/2004GL021782.

Dye, J. E., and J. C. Willett, 2007: Observed enhancement of reflectivity and electric field in long-lived Florida anvils. Mon. Wea. Rev., 135, 3362-3380, https://doi.org/10.1175/ MWR3484.1.

Eddy, A. J., 2018: Environmental conditions producing thunderstorms with anomalous vertical polarity of charge structure. M.S. thesis, Dept. of Meteorology, University of Oklahoma, $127 \mathrm{pp}$.

Fan, X. P., Y. J. Zhang, D. Zheng, Y. Zhang, W. T. Lyu, H. Y. Liu, and L. T. Xu, 2018: A new method of three-dimensional location for low-frequency electric field detection array. J. Geophys. Res. Atmos., 123, 8792-8812, https://doi.org/ 10.1029/2017JD028249.

Fierro, A. O., M. S. Gilmore, E. R. Mansell, L. J. Wicker, and J. M. Straka, 2006: Electrification and lightning in an idealized boundary-crossing supercell simulation of 2 June 1995. Mon. Wea. Rev., 134, 3149-3172, https://doi.org/10.1175/ MWR3231.1.

Fleenor, S., C. J. Biagi, K. L. Cummins, E. P. Krider, and X.-M. Shao, 2009: Characteristics of cloud-to-ground lightning in warm-season thunderstorms in the central Great Plains. Atmos. Res., 91, 333-352, https://doi.org/10.1016/ j.atmosres.2008.08.011.

Fortenbaugh, W. W., and D. Gutas, 1992: Theophrastus: His Psychological, Doxographical, and Scientific Writings. Transaction Publishers, $410 \mathrm{pp}$.

Goehring, J. W., 2005: The electrification of a severe multicell thunderstorm: A study of the STEPS 19 June 2000 storm. M.S. dissertation, Institute of Atmospheric Sciences, South Dakota School of Mines and Technology, $110 \mathrm{pp}$.

Grant, I. S., and W. R. Phillips, 1988: Electromagnetism. Manchester Physics Series, Wiley, $514 \mathrm{pp}$.

Gungle, B., and E. P. Krider, 2006: Cloud-to-ground lightning and surface rainfall in warm-season Florida thunderstorms. J. Geophys. Res., 111, D19203, https://doi.org/10.1029/ 2005JD006802.

Hallett, J., and S. C. Mossop, 1974: Production of secondary ice particles during the riming process. Nature, 249, 26-28, https:// doi.org/10.1038/249026a0.

_- R. I. Sax, D. Lamb, and A. S. Ramachandra Murty, 1978: Aircraft measurements of ice in Florida cumuli. Quart. J. Roy. Meteor. Soc., 104, 631-651, https://doi.org/10.1002/ qj.49710444108.

Helsdon, J. H., and R. D. Farley, 1987: A numerical modeling study of a Montana thunderstorm: 2. Model results versus observations involving electrical aspects. J. Geophys. Res., 92, 56615675, https://doi.org/10.1029/JD092iD05p05661.

— W. A. Wojcik, and R. D. Farley, 2001: An examination of thunderstorm charging mechanisms using a two-dimensional storm electrification model. J. Geophys. Res., 106, 1165-1192, https://doi.org/10.1029/2000JD900532.

—, S. Gattaleeradapan, R. D. Farley, and C. Waits, 2002: An examination of the convective charging hypothesis: Charge structure, electric fields, and Maxwell currents. J. Geophys. Res., 107, 4630, https://doi.org/10.1029/2001JD001495. 
Heymsfield, A. J., A. Bansemer, P. R. Field, S. L. Durden, J. L. Stith, J. E. Dye, W. Hall, and C. A. Grainger, 2002: Observations and parameterizations of particle size distributions in deep tropical cirrus and stratiform precipitating clouds: Results from in situ observations in TRMM field campaigns. J. Atmos. Sci., 59, 3457-3491, https://doi.org/10.1175/1520-0469(2002)059<3457: OAPOPS $>2.0 . \mathrm{CO} ; 2$.

Hourdin, F., and Coauthors, 2017: The art and science of climate model tuning. Bull. Amer. Meteor. Soc., 98, 589-602, https:// doi.org/10.1175/BAMS-D-15-00135.1.

Jayaratne, R., and C. P. R. Saunders, 1984: The "rain gush", lightning and the lower positive charge center in thunderstorms. J. Geophys. Res., 89, 11 816-11818, https://doi.org/ 10.1029/JD089iD07p11816.

, and J. Hallett, 1983: Laboratory studies of the charging of soft hail during ice crystal interactions. Quart. J. Roy. Meteor. Soc., 109, 609-630, https://doi.org/10.1002/qj.49710946111.

Keith, W. D., and C. P. R. Saunders, 1989: Charge transfer during multiple large ice crystal interactions with a riming target. J. Geophys. Res., 94, 13 103-13 106, https://doi.org/10.1029/ JD094iD11p13103.

Khain, A., M. B. Pinsky, M. Shapiro, and A. Pokrovsky, 2001: Collision rate of small graupel and water drops. J. Atmos. Sci., 58, 2571-2595, https://doi.org/10.1175/1520-0469(2001)058<2571: CROSGA $>2.0 . \mathrm{CO} ; 2$.

—, A. Pokrovsky, M. Pinsky, A. Seifert, and V. T. J. Phillips, 2004: Simulation of effects of atmospheric aerosols on deep turbulent convective clouds using a spectral microphysics mixed-phase cumulus cloud model. Part I: Model description and possible applications. J. Atmos. Sci., 61, 2963-2982, https:// doi.org/10.1175/JAS-3350.1.

- D. Rosenfeld, and A. Pokrovsky, 2005: Aerosol impact on the dynamics and microphysics of deep convective clouds. Quart. J. Roy. Meteor. Soc., 131, 2639-2663, https://doi.org/10.1256/ qj.04.62.

— N. BenMoshe, and A. Pokrovsky, 2008: Factors determining the impact of aerosols on surface precipitation from clouds: An attempt at classification. J. Atmos. Sci., 65, 1721-1748, https://doi.org/10.1175/2007JAS2515.1.

Kinzer, G., 1974: Cloud-to-ground lightning versus radar reflectivity in Oklahoma thunderstorms. J. Atmos. Sci., 31, 787-799, https:// doi.org/10.1175/1520-0469(1974)031<0787:CTGLVR>2.0.CO;2.

Kitagawa, N., and K. Michimoto, 1994: Meteorological and electrical aspects of winter thunderclouds. J. Geophys. Res., 99, 10 713-10721, https://doi.org/10.1029/94JD00288.

Koenig, L. R., 1963: The glaciating behavior of small cumulonimbus clouds. J. Atmos. Sci., 20, 29-47, https://doi.org/10.1175/ 1520-0469(1963)020<0029:TGBOSC $>2.0 . \mathrm{CO} ; 2$.

Korolev, A., 2007: Limitations of the Wegener-BergeronFindeisen mechanism in the evolution of mixed-phase clouds. J. Atmos. Sci., 64, 3372-3375, https://doi.org/10.1175/ JAS4035.1.

Krehbiel, P. R., R. J. Thomas, W. Rison, T. Hamlin, J. Harlin, and M. Davis, 2000: GPS-based mapping system reveals lightning inside storms. Eos, Trans. Amer. Geophys. Union, 81, 21-32, https://doi.org/10.1029/00EO00014.

—, J. A. Riousset, V. P. Pasko, R. J. Thomas, W. Rison, M. A. Stanley, and H. E. Edens, 2008: Upward electrical discharges from thunderstorms. Nat. Geosci., 1, 233-237, https://doi.org/ 10.1038/ngeo162.

Kudzotsa, I., 2014: Mechanisms of aerosol indirect effects on glaciated clouds simulated numerically. Ph.D. dissertation, University of Leeds, 200 pp.
— - and Coauthors, 2016: Aerosol indirect effects on glaciated clouds. Part I: Model description. Quart. J. Roy. Meteor. Soc., 142, 1958-1969, https://doi.org/10.1002/qj.2791.

Kuettner, J., 1950: The electrical and meteorological conditions inside thunderclouds. J. Meteor., 7, 322-332, https://doi.org/ 10.1175/1520-0469(1950)007<0322:TEAMCI>2.0.CO;2.

Kuhlman, K. M., 2004: Numerical simulations of the 29 June 2000 STEPS tornadic supercell: Microphysics, electrification, and lightning. M.S. thesis, Dept. of Meteorology, University of Oklahoma, $72 \mathrm{pp}$.

—_, C. L. Ziegler, E. R. Mansell, D. R. MacGorman, and J. M. Straka, 2006: Numerically simulated electrification and lightning of the 29 June 2000 STEPS supercell storm. Mon. Wea. Rev., 134, 2734-2757, https://doi.org/10.1175/ MWR3217.1.

_- D. R. MacGorman, M. I. Biggerstaff, and P. R. Krehbiel, 2009: Lightning initiation in the anvils of two supercell storms. Geophys. Res. Lett., 36, L07802, https://doi.org/ 10.1029/2008GL036650.

Kumar, P. P., and C. P. R. Saunders, 1989: Charge transfer during single crystal interaction with a rimed target. J. Geophys. Res., 94, 13 099-13 102, https://doi.org/10.1029/ JD094iD11p13099.

Lang, T. J., S. A. Rutledge, J. E. Dye, M. Venticinque, P. Laroche, and E. Defer, 2000: Anomalously low negative cloud-to-ground lightning flash rates in intense convective storms observed during STERAO-A. Mon. Wea. Rev., 128, 160-173, https://doi.org/10.1175/1520-0493(2000)128<0160: ALNCTG $>2.0 . \mathrm{CO} ; 2$.

— , and Coauthors, 2004: The Severe Thunderstorm Electrification and Precipitation Study (STEPS). Bull. Amer. Meteor. Soc., 85, 1107-1126, https://doi.org/10.1175/BAMS-85-8-1107.

Latham, J., 1981: The electrification of thunderstorms. Quart. J. Roy. Meteor. Soc., 107, 277-298, https://doi.org/10.1002/ qj.49710745202.

_ , and J. E. Dye, 1989: Calculations on the electrical development of a small thunderstorm. J. Geophys. Res., 94, 1314113144, https://doi.org/10.1029/JD094iD11p13141.

Leal, A. F. R., V. A. Rakov, and B. R. P. Rocha, 2019: Compact intracloud discharges: New classification of field waveforms and identification by lightning locating systems. Electr. Power Syst. Res., 173, 251-262, https://doi.org/10.1016/ j.epsr.2019.04.016.

Liu, C., E. R. Williams, E. J. Zipser, and G. Burns, 2010: Diurnal variation of global thunderstorms and electrified shower clouds and their contribution to the global electrical circuit. J. Atmos. Sci., 67, 309-323, https://doi.org/10.1175/ 2009JAS3248.1.

Lyu, F., and Coauthors, 2014: A low-frequency near-field interferometric-TOA 3-D lightning mapping array. Geophys. Res. Lett., 41, 7777-7784, https://doi.org/10.1002/2014GL061963.

_ , S. A. Cummer, G. Lu, X. Zhou, and J. Weinert, 2016: Imaging lightning intracloud initial stepped leaders by low-frequency interferometric lightning mapping array. Geophys. Res. Lett., 43, 5516-5523, https://doi.org/10.1002/2016GL069267.

MacGorman, D. R., and W. D. Rust, 1998: The Electrical Nature of Storms. Oxford University Press, $422 \mathrm{pp}$.

_- J. M. Straka, and C. L. Ziegler, 2001: A lightning parameterization for numerical cloud models. J. Appl. Meteor., 40, 459-478, https://doi.org/10.1175/1520-0450(2001)040<0459: ALPFNC $>2.0 . C O ; 2$.

Mach, D. M., R. J. Blakeslee, M. G. Bateman, and J. C. Bailey, 2010: Comparisons of total currents based on storm location, 
polarity, and flash rates derived from high-altitude aircraft overflights. J. Geophys. Res., 115, D03201, https://doi.org/ 10.1029/2009JD012240.

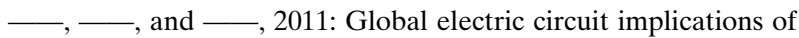
combined aircraft storm electric current measurements and satellite-based diurnal lightning statistics. J. Geophys. Res., 116, D05201, https://doi.org/10.1029/2010JD014462.

Magono, C., 1977: Precipitation electricity of thunderclouds and shower clouds. Proc. Int. Conf. on Atmospheric Electricity, Garmisch-Partenkirchen, Germany, ICAE, 368-378.

Mansell, E. R., D. R. MacGorman, C. L. Ziegler, and J. M. Straka, 2002: Simulated three-dimensional branched lightning in a numerical thunderstorm model. J. Geophys. Res., 107, 4075, https://doi.org/10.1029/2000JD000244.

$-, \ldots, \ldots$, and $—, 2005$ : Charge structure and lightning sensitivity in a simulated multicell thunderstorm. J. Geophys. Res., 110, D12101, https://doi.org/10.1029/2004JD005287.

— C. L. Ziegler, and E. R. Bruning, 2010: Simulated electrification of a small thunderstorm with two-moment bulk microphysics. J. Atmos. Sci., 67, 171-194, https://doi.org/10.1175/ 2009JAS2965.1.

Markson, R., 2007: The global circuit intensity: Its measurement and variation over the last 50 years. Bull. Amer. Meteor. Soc., 88, 223-242, https://doi.org/10.1175/BAMS-88-2-223.

Marshall, B. H. P., J. Latham, and C. P. R. Saunders,1978: A laboratory study of charge transfer accompanying collision of ice crystals with a simulated hailstone. Quart. J. Roy. Meteor. Soc., 104, 163-178, https://doi.org/10.1002/qj.49710443912.

Marshall, T. C., M. McCarthy, and W. D. Rust, 1995: Electric field magnitudes and lightning initiation in thunderstorms. J. Geophys. Res., 100, 7097-7103, https://doi.org/10.1029/95JD00020.

Murphy, J. M., B. B. B. Booth, M. Collins, G. R. Harris, D. M. H. Sexton, and M. J. Webb, 2007: A methodology for probabilistic predictions of regional climate change from perturbed physics ensembles. Philos. Trans. Roy. Soc., 365A, 1993-2028, https://doi.org/10.1098/rsta.2007.2077.

Orville, R. E., and G. R. Huffines, 2001: Cloud-to-ground lightning in the United States: NLDN results in the first decade, 198998. Mon. Wea. Rev., 129, 1179-1193, https://doi.org/10.1175/ 1520-0493(2001)129<1179:CTGLIT>2.0.CO;2.

Pereyra, R. G., E. E. Avila, N. E. Castellano, and C. P. R. Saunders, 2000: A laboratory study of graupel charging. J. Geophys. Res., 105, 20 803-20 812, https://doi.org/10.1029/2000JD900244.

— , R. E. Burgesser, and E. E. Avila, 2008: Charge separation in thunderstorm conditions. J. Geophys. Res., 113, D17203, https://doi.org/10.1029/2007JD009720.

Phillips, V. T. J., A. M. Blyth, T. W. Choularton, P. R. A. Brown, and J. Latham, 2001: The glaciation of a cumulus cloud over New Mexico. Quart. J. Roy. Meteor. Soc., 127, 1513-1534, https://doi.org/10.1002/qj.49712757503.

— , T. W. Choularton, A. M. Blyth, and J. Latham, 2002: The influence of aerosol concentrations on the glaciation and precipitation of a cumulus cloud. Quart. J. Roy. Meteor. Soc., 128, 951-971, https://doi.org/10.1256/0035900021643601.

— , and Coauthors, 2005: Anvil glaciation in a deep cumulus updraft over Florida simulated with an explicit microphysics model. I: The impact of various nucleation processes. Quart. J. Roy. Meteor. Soc., 131, 2019-2046, https://doi.org/10.1256/ qj.04.85.

_ L. L. J. Donner, and S. Garner, 2007: Nucleation processes in deep convection simulated by a cloud-system-resolving model with double-moment bulk microphysics. J. Atmos. Sci., 64, 738-761, https://doi.org/10.1175/JAS3869.1.
— P. J. DeMott, and C. Andronache, 2008: An empirical parameterization of heterogeneous ice nucleation for multiple chemical species of aerosol. J. Atmos. Sci., 65, 2757-2783, https://doi.org/10.1175/2007JAS2546.1.

, and Coauthors, 2009: Potential impacts from biological aerosols on ensembles of continental clouds simulated numerically. Biogeosciences, 6, 987-1014, https://doi.org/10.5194/ bg-6-987-2009.

—, P. J. DeMott, C. Andronache, K. A. Pratt, K. A. Prather, R. Subramanian, and C. Twohy, 2013: Improvements to an empirical parameterization of heterogeneous ice nucleation and its comparison with observations. J. Atmos. Sci., 70, 378409, https://doi.org/10.1175/JAS-D-12-080.1.

— A. Khain, N. Benmoshe, and E. Ilotovitz, 2014: Theory of time-dependent freezing. Part I: Description of scheme for wet growth of hail. J. Atmos. Sci., 71, 4527-4557, https://doi.org/ 10.1175/JAS-D-13-0375.1.

- M. Formenton, A. Bansemer, I. Kudzotsa, and B. Lienert, 2015: A scheme of sticking efficiency for collisions of snow and graupel with ice crystals: Theory and comparison with observations. J. Atmos. Sci., 72, 4885-4902, https://doi.org/10.1175/ JAS-D-14-0096.1.

—, J.-I. Yano, and A. Khain, 2017a: Ice multiplication by breakup in ice-ice collisions. Part I: Theoretical formulation. J. Atmos. Sci., 74, 1705-1719, https://doi.org/10.1175/JAS-D16-0224.1.

— ice collisions. Part II: Numerical simulations. J. Atmos. Sci., 74, 2789-2811, https://doi.org/10.1175/JAS-D-16-0223.1.

_- S. Patade, J. Gutierrez, and A. Bansemer, 2018: Secondary ice production by fragmentation of freezing of drops: Formulation and theory. J. Atmos. Sci., 75, 3031-3070, https:// doi.org/10.1175/JAS-D-17-0190.1.

Piepgrass, M. V., E. P. Krider, and C. B. Moore, 1982: Lightning and surface rainfall during Florida thunderstorms. J. Geophys. Res., 87, 11 193-11 201, https://doi.org/ 10.1029/JC087iC13p11193.

Pinsky, M., A. P. Khain, and M. Shapiro, 2001: Collision efficiency of drops in a wide range of Reynolds numbers: Effects of pressure on spectrum evolution. J. Atmos. Sci., 58, 742-764, https://doi.org/10.1175/1520-0469(2001)058<0742:CEODIA $>$ 2.0.CO;2.

Proctor, D. E., 1991: Regions where lightning flashes began. J. Geophys. Res., 96, 5099-5112, https://doi.org/10.1029/ 90JD02120.

Pruppacher, H., and J. Klett, 1997: Microphysics of Clouds and Precipitation. Kluwer Academic Publishers, 954 pp.

Rakov, V. A., and M. A. Uman, 2003: Lightning: Physics and Effects. Cambridge University Press, 687 pp.

Reap, R. M., and D. R. MacGorman, 1989: Cloud-to-ground lightning: Climatological characteristics and relationships to model fields, radar observations, and severe local storms. Mon. Wea. Rev., 117, 518-535, https://doi.org/10.1175/15200493(1989)117<0518:CTGLCC > 2.0.CO;2.

Reynolds, S. E., M. Brook, and M. F. Gourley, 1957: Thunderstorm charge separation. J. Meteor., 14, 426-436, https://doi.org/ 10.1175/1520-0469(1957)014<0426:TCS >2.0.CO;2.

Riousset, J. A., V. P. Pasko, P. R. Krehbiel, R. J. Thomas, and W. Rison, 2007: Three-dimensional fractal modeling of intracloud lightning discharge in a New Mexico thunderstorm and comparison with lightning mapping observations. J. Geophys. Res., 112, D15203, https://doi.org/ 10.1029/2006JD007621. 
Rison, W., R. J. Thomas, P. R. Krehbiel, T. Hamlin, and J. Harlin, 1999: A GPS-based three-dimensional lightning mapping system: Initial observations in central New Mexico. Geophys. Res. Lett., 26, 3573-3576, https://doi.org/10.1029/ 1999GL010856.

Rosenfeld, D., and I. M. Lensky, 1998: Satellite-based insights into precipitation formation processes in continental and maritime convective clouds. Bull. Amer. Meteor. Soc., 79, 2457-2476, https://doi.org/10.1175/1520-0477(1998)079<2457: SBIIPF $>2.0 . C O ; 2$.

Rust, W. D., and C. B. Moore, 1974: Electrical conditions near the base of thunderclouds over New Mexico. Quart. J. Roy. Meteor. Soc., 100, 450-468, https://doi.org/10.1002/ qj.49710042516.

—, D. R. MacGorman, and R. T. Arnold, 1981: Positive cloud-toground lightning flashes in severe storms. Geophys. Res. Lett., 8, 791-794, https://doi.org/10.1029/GL008i007p00791.

Rycroft, M. J., S. Israelsson, and C. Price, 2000: The global atmospheric electric circuit, solar activity and climate change. J. Atmos. Sol.-Terr. Phys., 62, 1563-1576, https://doi.org/10.1016/ S1364-6826(00)00112-7.

Saunders, C. P. R., and S. L. Peck, 1998: Laboratory studies of the influence of the rime accretion rate on charge transfer during crystal/graupel collisions. J. Geophys. Res., 103, 13 949-13 956, https://doi.org/10.1029/97JD02644.

— D. Keith, and R. P. Mitzeva, 1991: The effect of liquid water on thunderstorm charging. J. Geophys. Res., 96,11 007-11 017, https://doi.org/10.1029/91JD00970.

—, H. Bax-Norman, C. Emersic, E. E. Avila, and N. E. Castellano, 2006: Laboratory studies of the effect of cloud conditions on graupel/crystal charge transfer in thunderstorm electrification. Quart. J. Roy. Meteor. Soc., 132, 2653-2673, https://doi.org/10.1256/qj.05.218.

Schoene, J., M. A. Uman, and V. A. Rakov, 2010: Return stroke peak current versus charge transfer in rocket-triggered lightning. J. Geophys. Res., 115, D12107, https://doi.org/10.1029/ 2009JD013066.

Simpson, G., 1949: Atmospheric electricity during disturbed weather. Geophys. Mem. London, 84, 1-51.

Skamarock, W. C., J. B. Klemp, J. Dudhia, D. O. Gill, D. M. Barker, W. Wang, and J. G. Powers, 2005: A description of the Advanced Research WRF version 2. NCAR Tech. Note NCAR/TN468+STR, 88 pp., https://doi.org/10.5065/D6DZ069T.

Soula, S., S. Chauzy, M. Chong, S. Coquillat, J. F. Georgis, Y. Seity, and P. Tabary, 2003: Surface precipitation electric current produced by convective rains during the Mesoscale Alpine Program. J. Geophys. Res., 108, 4395, https://doi.org/10.1029/ 2001JD001588.

Takahashi, T., 1978: Riming electrification as a charge generation mechanism in thunderstorms. J. Atmos. Sci., 35, 1536-1548, https://doi.org/10.1175/1520-0469(1978)035<1536: REAACG $>2.0 . \mathrm{CO} ; 2$.

- 1984: Thunderstorm electrification-A numerical study. J. Atmos. Sci., 41, 2541-2558, https://doi.org/10.1175/15200469(1984)041<2541:TENS > 2.0.CO;2.

_ 1987: Determination of lightning origins in a thunderstorm model. J. Meteor. Soc. Japan, 65, 777-794, https://doi.org/10.2151/ jmsj1965.65.5_777.

_ , and K. Miyawaki, 2002: Reexamination of riming electrification in a wind tunnel. J. Atmos. Sci., 59, 1018-1025, https://doi.org/ 10.1175/1520-0469(2002)059<1018:ROREIA > 2.0.CO;2.

— , S. Sugimoto, T. Kewano, and K. Suzuki, 2017: Riming electrification in Hokuriku winter clouds and comparison with laboratory observations. J. Atmos. Sci., 74, 431-447, https:// doi.org/10.1175/JAS-D-16-0154.1.

Tan, Y., S. Tao, Z. Liang, and B. Zhu, 2014: Numerical study on relationship between lightning types and distribution of space charge and electric potential. J. Geophys. Res. Atmos., 119, 1003-1014, https://doi.org/10.1002/2013JD019983.

Tessendorf, S. A., S. A. Rutledge, and K. C. Wiens, 2007: Radar and lightning observations of normal and inverted polarity multicellular storms from STEPS. Mon. Wea. Rev., 135, 36823706, https://doi.org/10.1175/2007MWR1954.1.

van den Heever, S. C., G. G. Carrio, W. R. Cotton, P. J. DeMott, and A. J. Prenni, 2006: Impacts of nucleating aerosol on Florida storms. Part I: Mesoscale simulations. J. Atmos. Sci., 63, 1752-1775, https://doi.org/10.1175/JAS3713.1.

Vardiman, L., 1978: The generation of secondary ice particles in clouds by crystal-crystal collision. J. Atmos. Sci., 35, 2168-2180, https://doi.org/10.1175/1520-0469(1978)035<2168: TGOSIP $>2.0 . \mathrm{CO} ; 2$.

Wahlin, L., 1986: Atmospheric Electrostatics. Wiley, 120 pp.

Weiss, S. A., D. R. MacGorman, and K. M. Calhoun, 2012: Lightning in the anvils of supercell thunderstorms. Mon. Wea. Rev., 140, 2064-2079, https://doi.org/10.1175/MWRD-11-00312.1.

Wiens, K. C., S. A. Rutledge, and S. A. Tessendorf, 2005: The 29 June 2000 supercell observed during STEPS. Part II: Lightning and charge structure. J. Atmos. Sci., 62, 4151-4177, https://doi.org/10.1175/JAS3615.1.

Williams, E. R., 1989: The tripole structure of thunderstorms. J. Geophys. Res., 94, 13151-13167, https://doi.org/10.1029/ JD094iD11p13151.

- 2001: The electrification of severe storms. Severe Convective Storms, Meteor. Monogr., No. 50, Amer. Meteor. Soc., 527528, https://doi.org/10.1175/0065-9401-28.50.527.

, 2018: Lightning activity in winter storms: A meteorological and cloud microphysical perspective. IEEJ Trans. Power Energy, 138, 364-373, https://doi.org/10.1541/ieejpes.138.364.

_ , and R. Zhang, 1996: Density of rime in laboratory simulations of thunderstorm microphysics and electrification. J. Geophys. Res., 101, 29 715-29 719, https://doi.org/10.1029/96JD03216.

_ , and S. Stanfill, 2002: The physical origin of the land-ocean contrast in lightning activity. C. R. Phys., 3, 1277-1292, https:// doi.org/10.1016/S1631-0705(02)01407-X.

_ , and E. Mareev, 2014: Recent progress on the global electrical circuit. Atmos. Res., 135-136, 2008-2027, https://doi.org/10.1016/ j.atmosres.2013.05.015.

—_, C. M. Cooke, and K. A. Wright, 1985: Electrical discharge propagation in and around space charge clouds. J. Geophys. Res., 90, 6059-6070, https://doi.org/10.1029/ JD090iD04p06059.

_, R. Zhang, and J. Rydock, 1991: Mixed-phase microphysics and cloud electrification. J. Atmos. Sci., 48, 2195-2203, https://doi.org/ 10.1175/1520-0469(1991)048<2195:MPMACE > 2.0.CO;2.

, and Coauthors, 1999: The behavior of total lightning activity in severe Florida thunderstorms. Atmos. Res., 51, 245-265, https://doi.org/10.1016/S0169-8095(99)00011-3.

_ , V. Mushtak, D. Rosenfeld, S. Goodman, and D. Boccippio, 2005: Thermodynamic conditions favorable to superlative thunderstorm updraft, mixed phase microphysics and lightning flash rate. Atmos. Res., 76, 288-306, https://doi.org/ 10.1016/j.atmosres.2004.11.009.

Wilson, C. T. R., 1921: Investigations on lightning discharges and on the electric field of thunderstorms. Philos. Trans. Roy. Soc., 221A, 73-115, https://doi.org/10.1098/rsta.1921.0003. 
, 1929: Some thundercloud problems. J. Franklin Inst., 208, 1-12. Winn, W. P., C. B. Moore, C. R. Holmes, and L. G. Byerley III, 1978: A thunderstorm of July 16, 1975, over Langmuir laboratory: A case study. J. Geophys. Res., 83, 3079-3092, https://doi.org/10.1029/JC083iC06p03079.

Wormell, T. W., 1953: Lightning. Quart. J. Roy. Meteor. Soc., 79, 474-489, https://doi.org/10.1002/qj.49707934203.

Zeng, X., and Coauthors, 2009: An indirect effect of ice nuclei on atmospheric radiation. J. Atmos. Sci., 66, 41-61, https:// doi.org/10.1175/2008JAS2778.1.
Zheng, D., D. Shi, Y. Zhang, Y. Zhang, W. Lyu, and Q. Meng, 2019: Initial leader properties during the preliminary breakdown processes of lightning flashes and their associations with initiation positions. J. Geophys. Res. Atmos., 124, 8025-8042, https://doi.org/10.1029/2019JD030300.

Zipser, E. J., and K. R. Lutz, 1994: The vertical profile of radar reflectivity of convective cells-A strong indicator of storm intensity and lightning probability? Mon. Wea. Rev., 122, 1751-1759, https://doi.org/10.1175/1520-0493(1994)122<1751:TVPORR> 2.0.CO;2. 